\title{
A global climatology of wind-wave interaction
}

\author{
Article \\ Published Version
}

Hanley, K. E., Belcher, S. E. and Sullivan, P. P. (2010) A global climatology of wind-wave interaction. Journal of Physical Oceanography, 40 (6). pp. 1263-1282. ISSN 0022-3670 doi: https://doi.org/10.1175/2010JPO4377.1 Available at https://centaur.reading.ac.uk/7479/

It is advisable to refer to the publisher's version if you intend to cite from the work. See Guidance on citing.

Published version at: http://dx.doi.org/10.1175/2010JPO4377.1

To link to this article DOI: http://dx.doi.org/10.1175/2010JPO4377.1

Publisher: American Meteorological Society

Publisher statement: (c) Copyright [2010-06] American Meteorological Society (AMS). Permission to use figures, tables, and brief excerpts from this work in scientific and educational works is hereby granted provided that the source is acknowledged. Any use of material in this work that is determined to be "fair use" under Section 107 of the U.S. Copyright Act or that satisfies the conditions specified in Section 108 of the U.S. Copyright Act (17USC $\S 108$, as revised by P.L. 94-553) does not require the AMS's permission. Republication, systematic reproduction, posting in electronic form, such as on a web site or in a searchable database, or other uses of this material, except as exempted by the above statement, requires written permission or a license from the AMS. Additional details are provided in the AMS Copyright Policy, available on the AMS Web site located at (http://www.ametsoc.org/) or from the AMS at 617-227-2425 or copyright@ametsoc.org.

All outputs in CentAUR are protected by Intellectual Property Rights law, 
including copyright law. Copyright and IPR is retained by the creators or other copyright holders. Terms and conditions for use of this material are defined in the End User Agreement.

\section{www.reading.ac.uk/centaur}

\section{CentAUR}

Central Archive at the University of Reading

Reading's research outputs online 


\title{
A Global Climatology of Wind-Wave Interaction
}

\author{
KiRSTy E. HANLEY AND STEPHEN E. BELCHER \\ Department of Meteorology, University of Reading, Reading, United Kingdom \\ Peter P. Sullivan \\ National Center for Atmospheric Research, Boulder, Colorado
}

(Manuscript received 1 October 2009, in final form 6 January 2010)

\begin{abstract}
Generally, ocean waves are thought to act as a drag on the surface wind so that momentum is transferred downward, from the atmosphere into the waves. Recent observations have suggested that when long wavelength waves-which are characteristic of remotely generated swell-propagate faster than the surface wind, momentum can also be transferred upward. This upward momentum transfer acts to accelerate the nearsurface wind, resulting in a low-level wave-driven wind jet. Previous studies have suggested that the sign reversal of the momentum flux is well predicted by the inverse wave age, the ratio of the surface wind speed to the speed of the waves at the peak of the spectrum. Data from the 40-yr ECMWF Re-Analysis (ERA-40) have been used here to calculate the global distribution of the inverse wave age to determine whether there are regions of the ocean that are usually in the wind-driven wave regime and others that are generally in the wavedriven wind regime. The wind-driven wave regime is found to occur most often in the midlatitude storm tracks where wind speeds are generally high. The wave-driven wind regime is found to be prevalent in the tropics where wind speeds are generally light and swell can propagate from storms at higher latitudes. The inverse wave age is also a useful indicator of the degree of coupling between the local wind and wave fields. The climatologies presented emphasize the nonequilibrium that exists between the local wind and wave fields and highlight the importance of swell in the global oceans.
\end{abstract}

\section{Introduction}

Ocean surface waves are the medium that transfer momentum across the air-sea interface. Currently, all operational ocean-atmosphere models only allow the momentum flux $\tau_{\text {tot }}$ to be positive, from atmosphere to ocean. Recent observations during conditions when waves propagate faster than the wind have reported upward momentum flux from the waves to the atmosphere (e.g., Drennan et al. 1999; Grachev and Fairall 2001) and the occurrence of low-level wave-driven jets (e.g., Smedman et al. 1999). The wave-driven wind regime was first reported by Harris (1966), who showed in a laboratory wave tank that a progressive water wave leads to airflow in the direction of wave propagation.

Wind-wave equilibrium, or a fully developed sea, is a state of wind and wave alignment where the shape of

Corresponding author address: Kirsty E. Hanley, Department of Meteorology, University of Reading, Earley Gate, P.O. Box 243, Reading RG6 6BB, United Kingdom.

E-mail: k.e.hanley@rdg.ac.uk the wave spectrum and the peak frequency are both stationary in time. Such a sea state is usually described by asymptotic values of integrated spectral parameters: for example, significant wave height $H_{s}$ and the spectral peak frequency $f_{p}$. Pierson and Moskowitz (1964) used a carefully chosen dataset representative of fully developed seas to propose universal relations for fully developed asymptotic limits that are based on similarity analysis. Alves et al. (2003) have shown that the Pierson and Moskowitz (1964) fully developed asymptotic limit for the peak frequency can be expressed in terms of the wave age, $c_{p} /\left(U_{10} \cos \theta\right)$, as

$$
\frac{c_{p}}{\left(U_{10} \cos \theta\right)}=1.2,
$$

where $c_{p}$ is the peak phase speed of the waves, $U_{10}$ is the $10-\mathrm{m}$ wind speed, and $\theta$ is the relative angle between the wind and the waves. When $c_{p} /\left(U_{10} \cos \theta\right)<1.2$, waves grow by absorbing momentum from the wind.

In reality, the ocean is often fetch and duration limited so that fully developed seas are uncommon. Ocean waves 
occur over a broad range of wavelengths, ranging from a few centimeters to a few hundred meters, with contributions from both wind waves and swell. Wind waves are locally generated, short-wavelength waves that travel slower than the surface wind. They require momentum from the wind to grow and as a result are strongly coupled to the local wind field (Janssen 1989). In contrast, longwavelength swell waves are usually generated remotely by storms and can propagate thousands of kilometers across the ocean, without momentum input from the wind. Drennan et al. (2003) used data from five field campaigns to study the influence of wave age on the airsea momentum flux during pure wind sea conditions. They found that pure wind seas are frequent in coastal regions, in enclosed seas, and during extreme wind events; however, in the open ocean swell is usually present. The results of the Coupled Boundary Layers and Air-Sea Transfer (CBLAST) field campaign, which took place in the North Atlantic (Edson et al. 2007), demonstrated that in light wind conditions $\left(<4 \mathrm{~m} \mathrm{~s}^{-1}\right)$ winds and waves are usually in a state of nonequilibrium where $c_{p}$ exceeds $U_{10}$, indicating that remotely generated swell is present.

Until recently, it was thought that swell, which is weakly coupled to the local wind, does not interact with the airflow. Experiments have shown that swell does interact with the airflow by giving momentum to the wind and inducing a wave-driven wind. Measurements of $\tau_{\text {tot }}$ by Drennan et al. (1999) in Lake Ontario show that, for swell aligned with the wind, $\tau_{\text {tot }}$ may sometimes be negative. Observations by Smedman et al. $(1999,2003)$ in the Baltic Sea have shown that, during swell-dominated conditions, the wind profile is no longer logarithmic. They observed a wind speed maximum near or below the lowest wind speed measurement of $10 \mathrm{~m}$. From results obtained during several sea expeditions, Grachev and Fairall (2001) found that, in the equatorial west Pacific Ocean, upward momentum transfer occurs about $10 \%$ of the time. Calculations by Hanley and Belcher (2008), which were in agreement with the ocean observations of Grachev and Fairall (2001), demonstrated that the sign reversal of the air-sea momentum flux from positive (i.e., into the waves) to negative (i.e., out of the waves) occurs when the inverse wave age drops below about 0.15 . Therefore, the inverse wave age is chosen here as a simple but effective parameter to characterize the wind-wave regime: the wind-driven wave regime occurs when $\left(U_{10} \cos \theta\right) / c_{p}>$ $1 / 1.2=0.83$, and the wave-driven wind regime occurs when $0<\left(U_{10} \cos \theta\right) / c_{p}<0.15$.

In the intermediate range of inverse wave age, $0.15<$ $\left(U_{10} \cos \theta\right) / c_{p}<0.83$, the sea state is mixed; that is, it is composed of both wind sea and swell. In this range, there are both growing waves extracting momentum from the wind and fast waves imparting momentum to the wind.
It is likely a smooth transition from one regime to another. When $\left(U_{10} \cos \theta\right) / c_{p}>0.83$, there are waves in the spectrum moving faster than the wind, which put small amounts of momentum back into the atmosphere. Similarly, when $\left(U_{10} \cos \theta\right) / c_{p}<0.15$, there are still growing waves extracting momentum. Therefore the limits that have been chosen here to characterize each regime are not hard limits.

The global importance of swell has been identified by Chen et al. (2002), who collocated a global dataset of simultaneous measurements of $H_{s}$ and $U_{10}$ from the Ocean Topography Experiment/National Aeronautics and Space Administration (NASA) Scatterometer (TOPEX/ NSCAT) and TOPEX/Quick Scatterometer (TOPEX/ QuikSCAT) missions to observe the spatial pattern of both wind sea and swell. They determined the global distribution of wind waves and swell using the wind-wave relation for fully developed seas given by Hasselmann et al. (1988), assuming that measurements of $H_{s}$ less than the fully developed limit are from a growing sea and measurements of $H_{s}$ that are greater are swell. Chen et al. (2002) find that swell occurs more than $80 \%$ of the time in most of the world's oceans. They identify three "swell pools" in the tropics where the probability of swell is more than $95 \%$. In contrast, Chen et al. (2002) find that wind waves occur most frequently in the midlatitudes, decreasing to a minimum at the equator.

The goal of this paper is to use the 40-yr European Centre for Medium-Range Weather Forecasts (ECMWF) Re-Analysis (ERA-40) wave dataset to develop a new climatology of wind-wave interaction, as diagnosed by the inverse wave age. The availability of wave data makes it possible to construct a global climatology of wave processes and wind-wave interaction that accounts for both wind waves and swell. McWilliams and Restrepo (1999) construct a global wave climatology using wind data to parameterize the waves. This method assumes wind-wave equilibrium and therefore ignores remotely generated swell. When wave data are used, the complete spectrum can be considered. The first question addressed here is, to what extent is the local wave field coupled to the local wind field? In section 3, ERA-40 data are used to study the effects of a storm passing through the Southern Ocean and to compute climatologies of the 10-m wind speed and the peak wave phase speed. These climatologies illustrate that, in many regions, the local wave state is not tied to the local wind conditions and highlight the importance of swell in the global oceans.

A second question is, can the sea state be broadly categorized into two regimes, wind-driven waves or wavedriven winds? This question is addressed in section 4, where the ERA-40 data are used to produce a global climatology of inverse wave age. This will determine the 
regions of the ocean that are usually in the wind-driven wave regime and the regions that are predominantly in the wave-driven wind regime. The climatology of $\left(U_{10} \cos \theta\right) / c_{p}$ provides the spatial distribution of each regime but does not provide information about how frequently each regime occurs. Therefore, in section $4 \mathrm{~b}$ a different technique is used to determine the global frequency of occurrence of the two regimes.

\section{The ERA-40 wave data}

The ECMWF has produced a 45-yr global reanalysis of atmospheric and wave data called ERA-40 (Uppala et al. 2005), which covers the period September 1957-August 2002. The reanalysis is produced using the ECMWF Integrated Forecasting System, an atmosphere model coupled to a wave model. Global observations of the $10-\mathrm{m}$ wind speed obtained from shipborne and buoy measurements and, since August 1993, the European Remote Sensing Satellite (ERS) scatterometer are assimilated into ERA-40 using a variational assimilation scheme (de las Heras et al. 1994). Also, since August 1993 significant wave heights obtained from the ERS altimeter have been assimilated. Although the quality and coverage of the observations improves over the ERA- 40 period, the reanalysis ensures that the data are continuous.

The ERA-40 wave reanalysis is produced using the wave model WAM (Hasselmann et al. 1988). WAM is coupled to the atmosphere model by a sea-statedependent Charnock parameter devised by Janssen (1991). To produce the reanalysis, WAM is forced by the $10-\mathrm{m}$ winds from the latest $6-\mathrm{h}$ forecast on a $1.5^{\circ} \times 1.5^{\circ}$ global resolution grid with data stored every $6 \mathrm{~h}$. WAM computes the full two-dimensional wave spectrum from which a number of integrated parameters can be obtained: for example, the significant wave height, the mean wave period, and the mean wave direction. The ERA-40 reanalysis gives these diagnostics for the entire spectrum and also for both the wind-wave and swell components. The wind sea is defined as the part of the spectrum for which the friction velocity in the direction of wave propagation is greater than $0.05 \times c$, where $c$ is the frequencydependent phase speed. The rest of the spectrum is defined as swell (Hasselmann et al. 1988). Janssen et al. (1997) compared the analyzed wave data with independent buoy measurements and found a good agreement.

Caires et al. (2004) recommend the use of ERA-40 data for global wave studies because they compare better with observations than other available reanalyses [e.g., National Centers for Environmental Prediction-National Center for Atmospheric Research (NCEP-NCAR)]. Because of their superior agreement with observations, the ERA-40 wave data are considered to be the best data currently available to produce a global climatology of ocean wave processes and wind-wave interaction. However, Caires et al. (2004) find the ERA-40 dataset tends to underestimate wind speeds above $14 \mathrm{~m} \mathrm{~s}^{-1}$. Partly as a result of this, the high peaks in significant wave height are underestimated in the ERA-40 dataset.

\section{Surface wave characteristics}

To understand how the local wave field is coupled to the local wind field, the ERA-40 data are first used to study the global patterns of $U_{10}, H_{s}$, and $c_{p}$. The ERA-40 data provide the components of the $10-\mathrm{m}$ wind speed, $u_{10}$ and $v_{10}$, which define the magnitude and direction of $U_{10}$. The significant wave height is one of the diagnostics given in the ERA-40 wave data. The ERA-40 wave data also provide the peak period $T_{p}$ of the one-dimensional frequency spectrum. Each spectral component travels with its own phase velocity determined by the linear dispersion relation $c=g / \omega$, where the angular frequency $\omega=2 \pi f$. The group of waves travels at the group velocity $c_{g}$ defined as the ratio of the group length to the group period (i.e., $c_{g}=d \omega / d k$ ). Using the linear dispersion relation, $c_{p}$ can be calculated from $T_{p}$ as

$$
c_{p}=\frac{g T_{p}}{2 \pi} .
$$

The mean wave direction $\left\langle\theta_{w}\right\rangle$ is also one of the diagnostics given in the ERA-40 wave data; therefore, $c_{p}$ has components $\left(c_{p} \sin \left\langle\theta_{w}\right\rangle, c_{p} \cos \left\langle\theta_{w}\right\rangle\right)$. The spectral peak generally represents the longer-wavelength waves; therefore, $c_{p}$ is a good measure of the speed of swell.

\section{a. A Southern Ocean storm}

To gain an understanding of the relationship between wind waves and swell, the ERA-40 wave data are first used to study $U_{10}$ and $c_{p}$ in the Indian Ocean after the passage of a storm in the adjacent part of the Southern Ocean between 14 and 16 July 1989.

Figure 1 shows the mean sea level pressure, $U_{10}$ and $c_{p}$ from the ERA-40 data at 0000 UTC 14 July. An intense low pressure system is building in the Southern Ocean at $45^{\circ} \mathrm{E}$ with a minimum mean sea level pressure of $940 \mathrm{mb}$. The highest wind speeds of $25 \mathrm{~m} \mathrm{~s}^{-1}$, which are located to the northwest of the low pressure center, have the potential to generate waves of $c_{p}=1.2 U_{10}=30 \mathrm{~m} \mathrm{~s}^{-1}$. At the center of the storm, wind speeds fall below $4 \mathrm{~m} \mathrm{~s}^{-1}$. The strong winds associated with the low pressure system generate waves with peak phase speeds equal to the maximum wind speeds of $24 \mathrm{~m} \mathrm{~s}^{-1}$. Both the wind and the waves move cyclonically around the low, showing that the waves here are strongly forced by the wind. At 
(a)

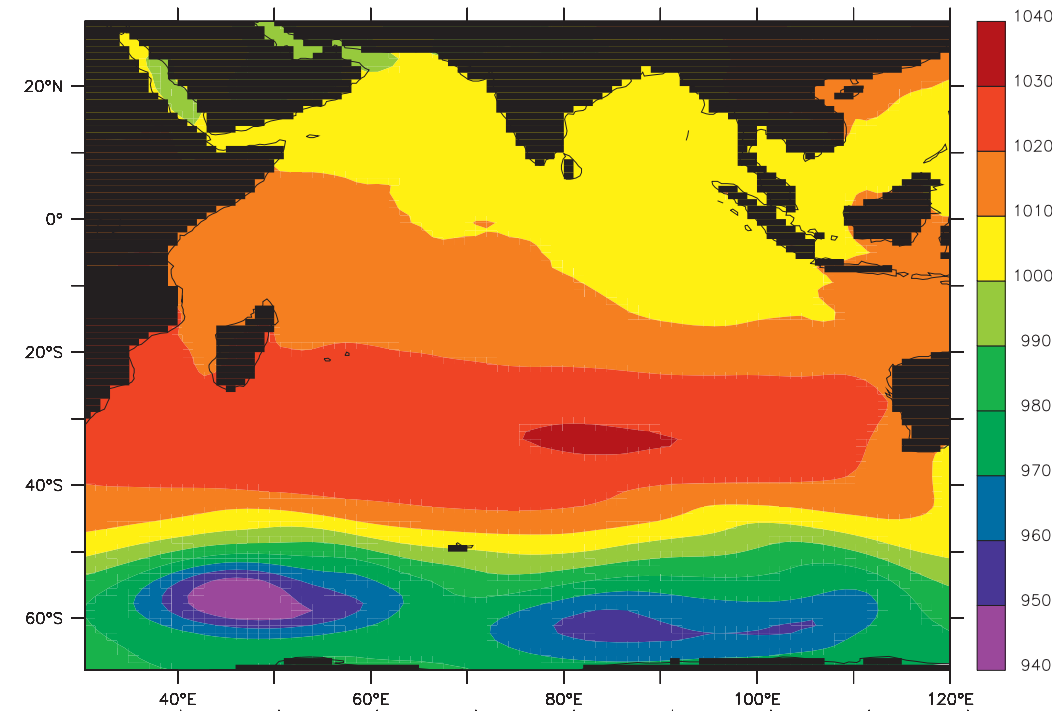

(b)
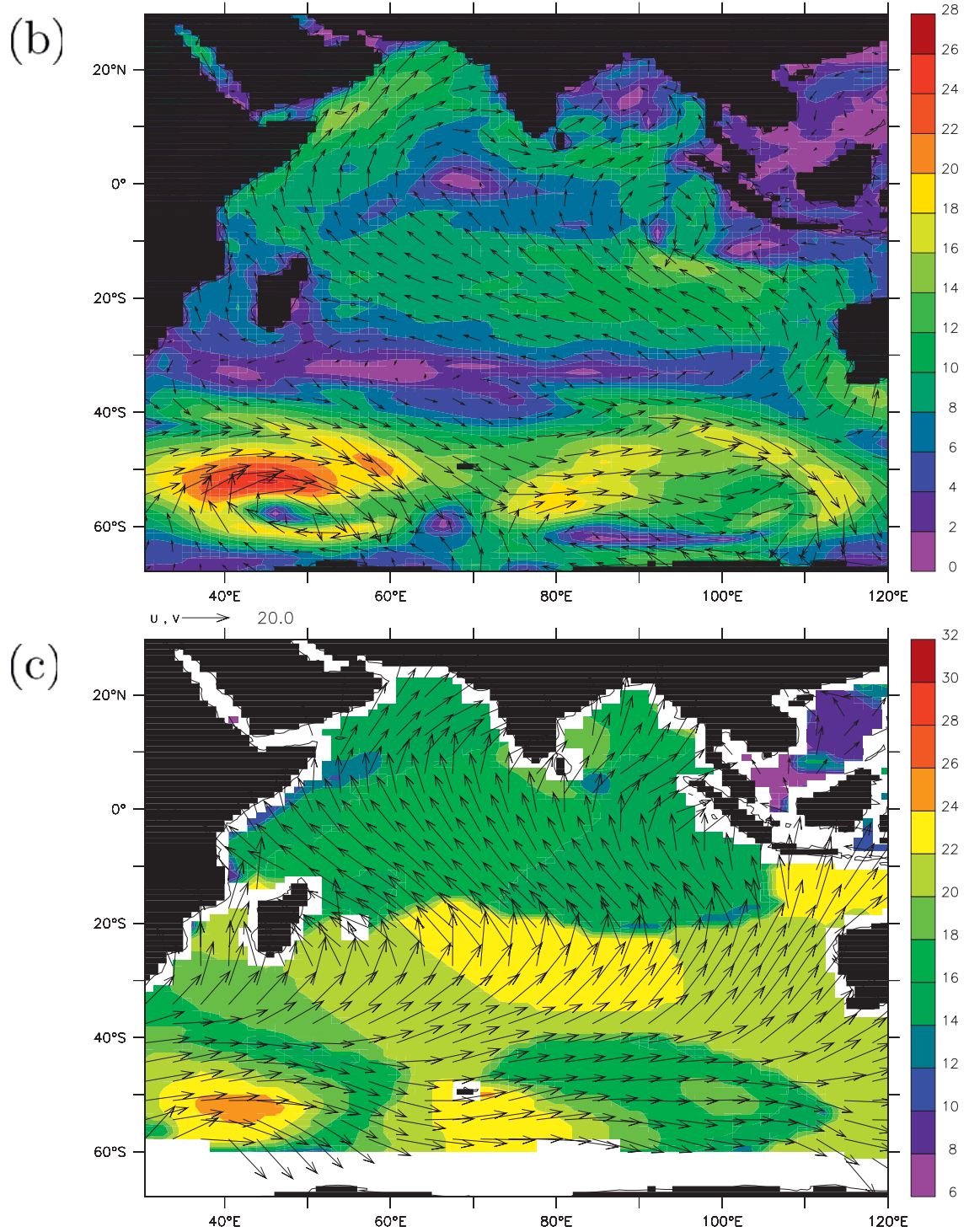

$\mathrm{CPX}, \mathrm{CPY} \longrightarrow 20.0$ 
$70^{\circ} \mathrm{E}$, there is a ridge of higher pressure between the low pressure system at $45^{\circ} \mathrm{E}$ and another low pressure system at $90^{\circ} \mathrm{E}$. Wind speeds in this region are reduced; however, $c_{p}$ exceeds $22 \mathrm{~m} \mathrm{~s}^{-1}$, indicating the presence of swell generated by the earlier storm. In the Indian Ocean, the mean sea level pressure is higher than in the Southern Ocean, with the maximum pressure of $1040 \mathrm{mb}$ occurring in the subtropics at $30^{\circ} \mathrm{S}$. The higher pressure means that $U_{10}$ is less in the Indian Ocean than in the Southern Ocean, rarely exceeding $12 \mathrm{~m} \mathrm{~s}^{-1}$. The peak wave speeds in the Indian Ocean are usually greater than the wind speeds, and the waves are generally not aligned with the wind, indicating that swell propagates out of the Southern Ocean into the Indian Ocean.

Figure 2 shows the evolution of $c_{p}$ and $U_{10}$ during the period 15-19 July 1989. The storm moves steadily eastward across the Southern Ocean during 15-17 July. As the storm progresses, a band of fast waves begins to propagate northeastward into the Indian Ocean. These waves are no longer aligned with the surface wind and are therefore characteristic of swell. As the swell moves across the Indian Ocean, $c_{p}$ continues to increase, even though the winds in this region are reduced. This is because ocean waves are dispersive: the faster waves outrun the slower waves so that the spectral peak is shifted toward the lower frequencies. In addition, nonlinear wind-wave interactions act to transfer energy from the high-frequency part of the spectrum to the low-frequency part, therefore increasing $c_{p}$ (Komen et al. 1994). As a result, the maximum values of $c_{p}$ occur at the front edge of the band. By 17 July, $c_{p}$ is already in excess of $28 \mathrm{~m} \mathrm{~s}^{-1}$. Ahead of the band, $c_{p}$ is generally less than $20 \mathrm{~m} \mathrm{~s}^{-1}$; however, $c_{p}$ is higher than $U_{10}$ and the surface wind and the waves are misaligned. This is an indication that swell from previous storms is present in the Indian Ocean.

Figures 2e,f show that, by 0000 UTC 17 July, the storm has almost passed through this region of the Southern Ocean. During the next $48 \mathrm{~h}$, the swell continues to move toward Indonesia with little attenuation of energy. In contrast, the storm in the Southern Ocean has almost decayed. By 0000 UTC 19 July (Fig. 2g), waves with peak phase speeds of $30 \mathrm{~m} \mathrm{~s}^{-1}$ have reached the coast of Indonesia. Over a period of $48 \mathrm{~h}, c_{p}$ has increased in this region by $\approx 12 \mathrm{~m} \mathrm{~s}^{-1}$. In contrast, the surface wind speeds in this region are consistently low between 17 and 19 July, with little change in direction.
Figures 2i,j show $c_{p}$ and $U_{10}$ averaged over 15-19 July 1989. Averaging over the storms life cycle acts to greatly smooth the peaks in both $c_{p}$ and $U_{10}$ : the maximum $c_{p}$ is reduced to $24 \mathrm{~m} \mathrm{~s}^{-1}$ and the maximum $U_{10}$ is reduced to $16 \mathrm{~m} \mathrm{~s}^{-1}$. Although the peak values of $U_{10}$ are relatively short lived, the high values of $c_{p}$ persist until the swell reaches the coast. Therefore, because the spatial and temporal extents of the maximum values of $c_{p}$ are much greater than the maximum values of $U_{10}$, the average $c_{p}$ is more than $1.2 U_{10}$.

The figures show that intense low pressure systems separated by ridges of higher pressure pass through the Southern Ocean. The strong winds associated with the low pressure systems generate fast-traveling wind waves. When wind speeds are reduced in the ridges between the lows, these waves become swell. A band of swell propagates out of the Southern Ocean toward the tropics. It can take up to 5 days for the swell to reach the tropics. This demonstrates that swell can travel thousands of kilometers across the ocean with very little attenuation, as reported by Snodgrass et al. (1966).

\section{b. Annual climatologies}

Now that we have established that intense low pressure systems passing through the Southern Ocean generate swell that can travel large distances across the ocean, the next aim is to study the annual climatologies of $U_{10}, H_{s}$, and $c_{p}$ to determine the coupling between the local wind field and the local wave field on a global scale.

Figure 3 shows $U_{10}, H_{s}$, and $c_{p}$ averaged over 19582001. The global surface wind pattern calculated using the ERA-40 data agrees well with previous climatologies of $U_{10}$ (e.g., Ahrens 2003). Figure 3a shows that the zonal component of the surface wind dominates over the meridional component. Wind speeds peak in the westerly orientated midlatitude storm tracks. In the Northern Hemisphere storm tracks, $U_{10}$ peaks at $10 \mathrm{~m} \mathrm{~s}^{-1}$ in the North Atlantic and $9 \mathrm{~m} \mathrm{~s}^{-1}$ in the North Pacific. In the Southern Ocean, the maximum wind speeds of $12 \mathrm{~m} \mathrm{~s}^{-1}$ occur between South America and Australia. The subtropical trade winds are found between $10^{\circ}$ and $30^{\circ}$. They move northeast in the Northern Hemisphere and southeast in the Southern Hemisphere with speeds ranging from 6 to $9 \mathrm{~m} \mathrm{~s}^{-1}$. Wind speeds are lowest, averaging less than $6 \mathrm{~m} \mathrm{~s}^{-1}$, in the intertropical convergence zone

FIG. 1. Conditions in the Southern Ocean at 0000 UTC 14 Jul 1989 calculated using the ERA-40 data (a) mean sea level pressure (mb), (b) 10-m wind speed ( $\mathrm{m} \mathrm{s}^{-1}$ ), and (c) peak phase speed $\left(\mathrm{m} \mathrm{s}^{-1}\right)$. Contours show magnitude and vectors show direction and magnitude. 
(a)

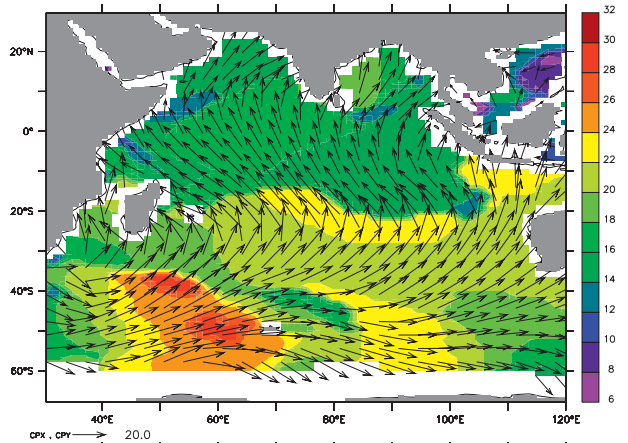

(c)

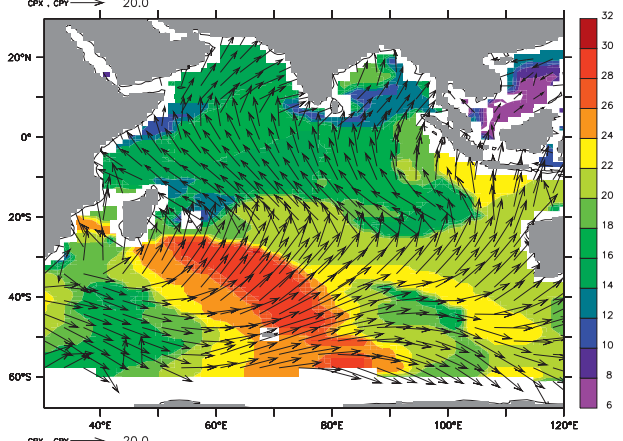

(e)

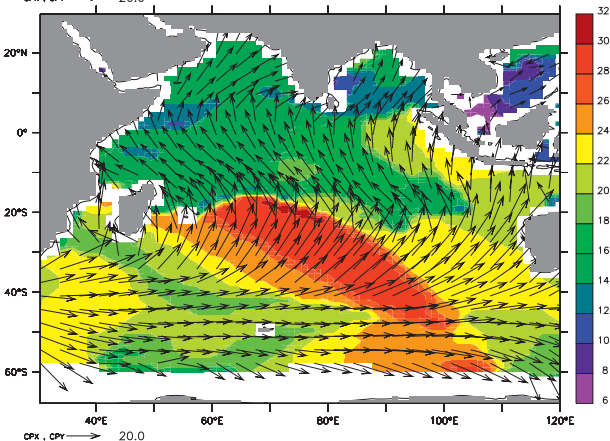

(g)

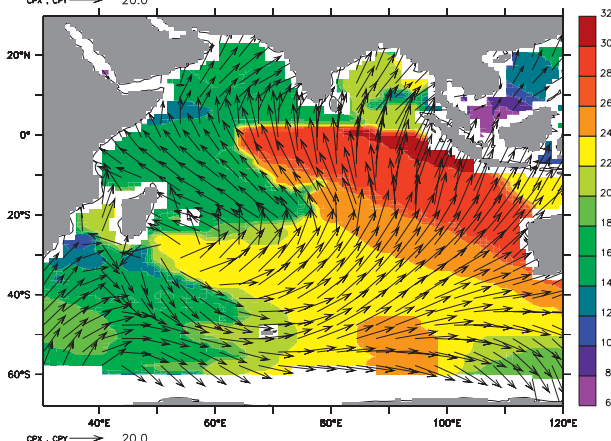

(i)

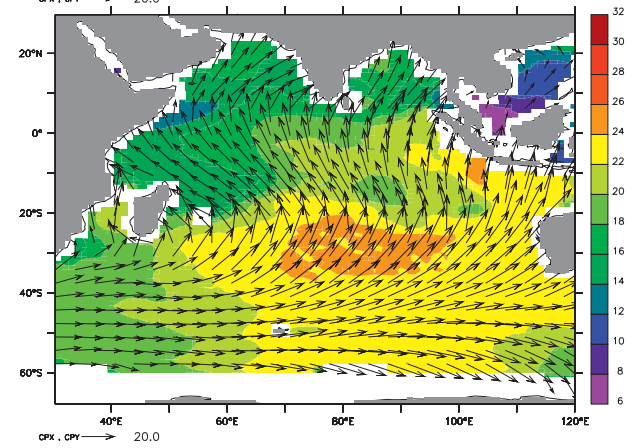

(b)

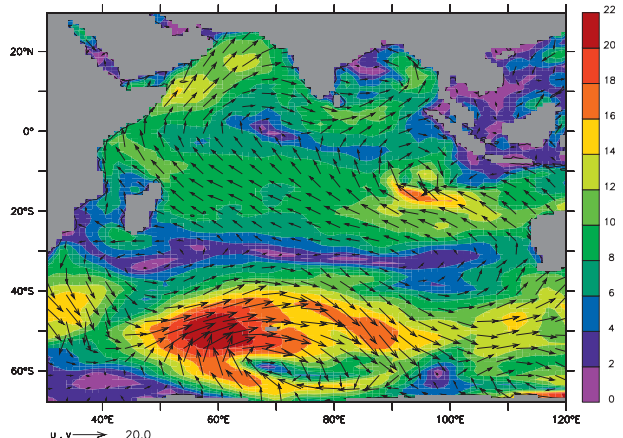

(d)

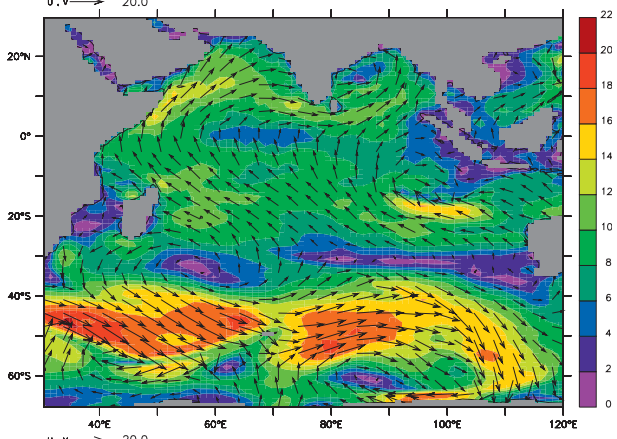

(f)

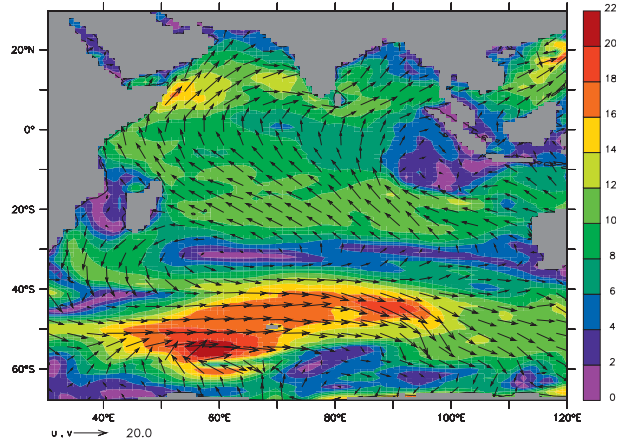

(h)

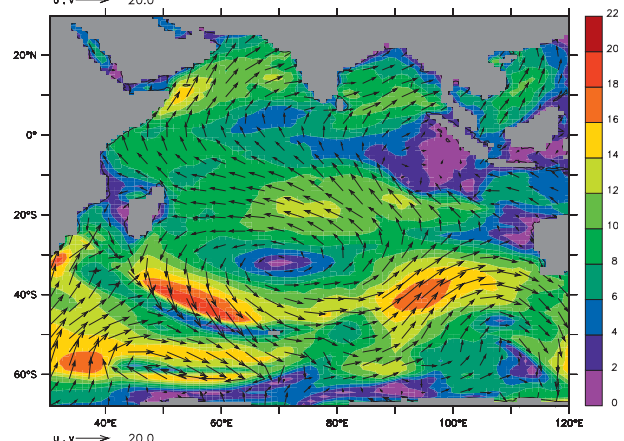

(j)

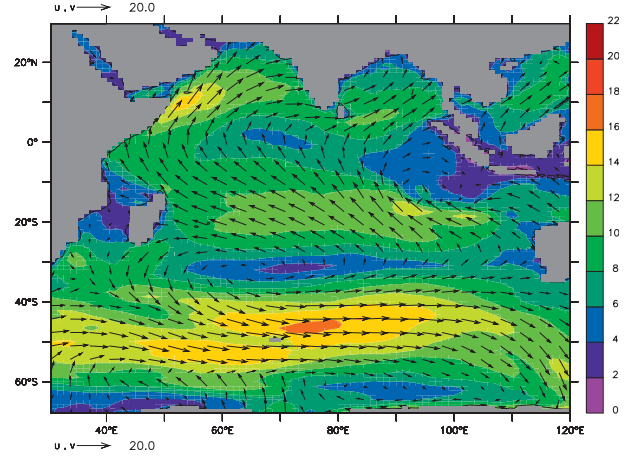


(ITCZ) between $10^{\circ} \mathrm{N}$ and $10^{\circ} \mathrm{S}$, where the wind systems from the two hemispheres meet.

From Fig. 3b, we see that there is a strong zonal pattern in $H_{s}$ with the highest wave conditions occurring in the midlatitude storm tracks. The peak values of $H_{s}$ occur in the same region of the Southern Ocean as the peak values of $U_{10}$, with the average values exceeding $4 \mathrm{~m}$ in this region. Because of the strong westerly winds, high wave conditions occur throughout the Southern Ocean, with $H_{s}$ surpassing $3.5 \mathrm{~m}$ in most areas. In the Northern Hemisphere storm tracks, where the winds are less than in the Southern Ocean, the average significant wave heights are also less, with the maximum averaged values in the range of 3-3.5 m. In the tropics, the significant wave heights are fairly uniform. Low wind speeds in these regions result in low wave heights, generally between 1.5 and $2.5 \mathrm{~m}$. The local increases in $U_{10}$ in the trade wind regions do not appear in the averaged significant wave height field, because the waves are composed of both local and nonlocal components, resulting in a smoother field. Overall, this shows that the wave heights are limited by the maximum wind speeds.

Figure $3 \mathrm{c}$ shows that there is a very distinct zonal variation in $c_{p}$ : waves are directed zonally in the storm tracks and meridionally elsewhere. The alignment of the wind and the waves gives an indication of whether a region is dominated by wind waves or swell. Generally, wind waves are aligned with the surface wind. Swell is generated remotely and therefore not usually aligned with the local surface wind. From Fig. 3, we see that $U_{10}$ and $c_{p}$ are aligned in the midlatitude storm tracks where wind speeds peak. Elsewhere, $U_{10}$ and $c_{p}$ are generally misaligned. This implies that wind waves occur most often in the midlatitude storm tracks with swell dominating elsewhere. This is consistent with the findings of Chen et al. (2002), who report that wind waves occur most frequently in the storm tracks and that swell occurs most often in the tropics.

Although Chen et al. (2002) find that wind waves occur most frequently in the midlatitude storm tracks, they also find that swell is present more than $75 \%$ of the time in these regions. Figure $3 \mathrm{c}$ shows that the annual average values of $c_{p}$ in the midlatitude storm tracks tend to exceed the fully developed values of $c_{p}=1.2 U_{10}$, suggesting that swell is also present in these regions. The case study described in section 3 a shows that wind speeds are not consistently high in the Southern Ocean, as suggested by the annual mean. The intense low pressure systems that pass through the Southern Ocean are separated by ridges of high pressure. Therefore, wind waves that are generated by the strong winds in the low pressure regions become swell when wind speeds are reduced in the ridges. The limited duration of the high winds in this region is also an indication that the wind waves are not fully developed.

Wind speeds in the midlatitude storm tracks are westerly, therefore swell propagating at the group velocity out of these regions has a westerly component. In Fig. 3c, a front is visible in the Pacific between Mexico and New Zealand and in the Atlantic between West Africa and Brazil that separates swell traveling south out of the Northern Hemisphere storm tracks from swell traveling north out of the Southern Ocean. As noted in section 3a, the peak wave speed continues to increase outside the midlatitude storm tracks, even though the wind forcing is reduced because ocean waves are dispersive. Therefore, the fastest waves occur at the western coasts of the tropical landmasses, with $c_{p}$ reaching $22 \mathrm{~m} \mathrm{~s}^{-1}$ in both the Indian and Pacific Oceans. These areas of maximum $c_{p}$ coincide with the swell pools identified by Chen et al. (2002). Figure $3 c$ shows that the fast waves in the Indian Ocean correspond to swell that has originated in the Southern Ocean between South Africa and Australia where $U_{10}$ peaks. The region off the west coast of the Americas is affected by swell propagating out of both the North Pacific and the Southern Ocean. The waves appear to have a stronger northward component suggesting that the area is dominated by swell from the Southern Ocean. The minimum values of $c_{p}$ occur in enclosed and semienclosed seas where the waves are limited by the available fetch.

\section{c. Seasonal variations}

Figure 4 shows $U_{10}$ averaged over 1958-2001 for the seasons December-February (DJF) and June-August (JJA). The peaks in $U_{10}$ are greatest in the winter hemisphere storm track and of larger magnitude than in the annual mean. Although the magnitudes of the peaks are similar in both hemispheres, the seasonal variability is greater in the Northern Hemisphere than in the Southern Hemisphere. The Northern Hemisphere experiences much lower winds in summer than the Southern Hemisphere

FIG. 2. (left) Peak phase speed ( $\mathrm{m} \mathrm{s}^{-1}$ ) and (right) 10-m wind speed at 0000 UTC in July 1989 on the (a),(b) 15th, (c),(d) 16th, (e),(f) 17th, (g),(h) 19th, and (i),(j) average over the 15th-19th. Contours show magnitude and vectors show direction and magnitude. 
(a)

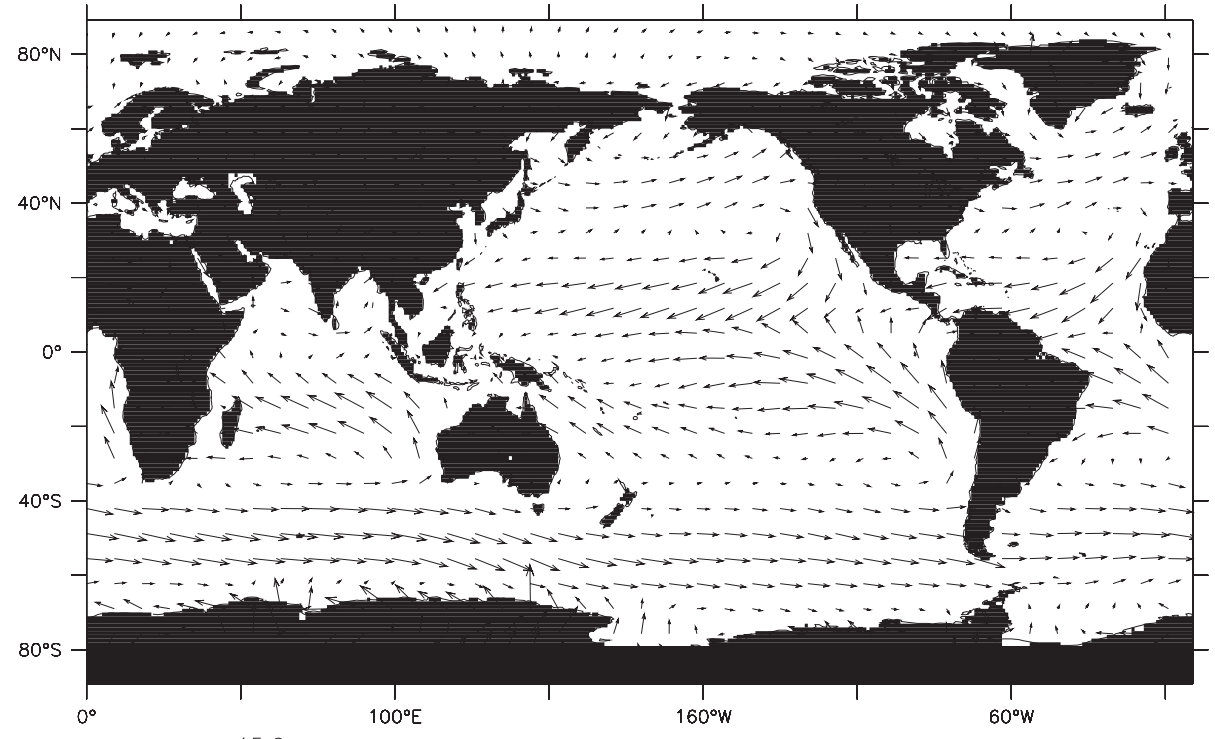

(b)

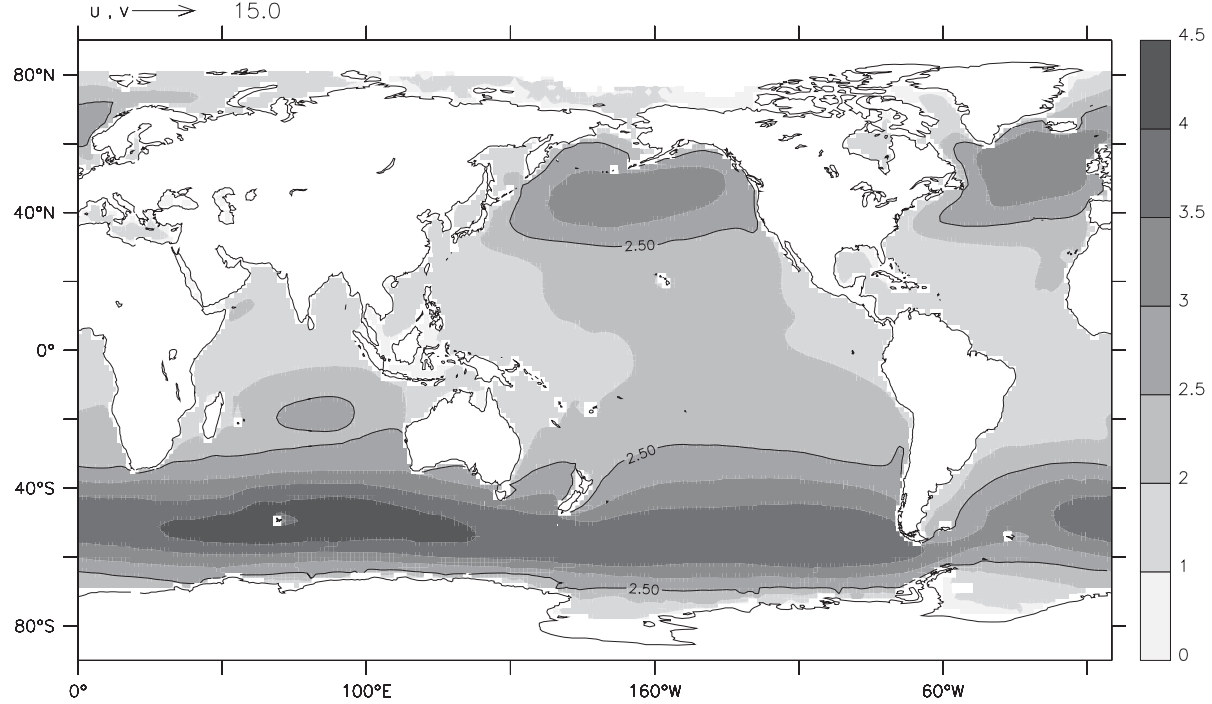

(c)

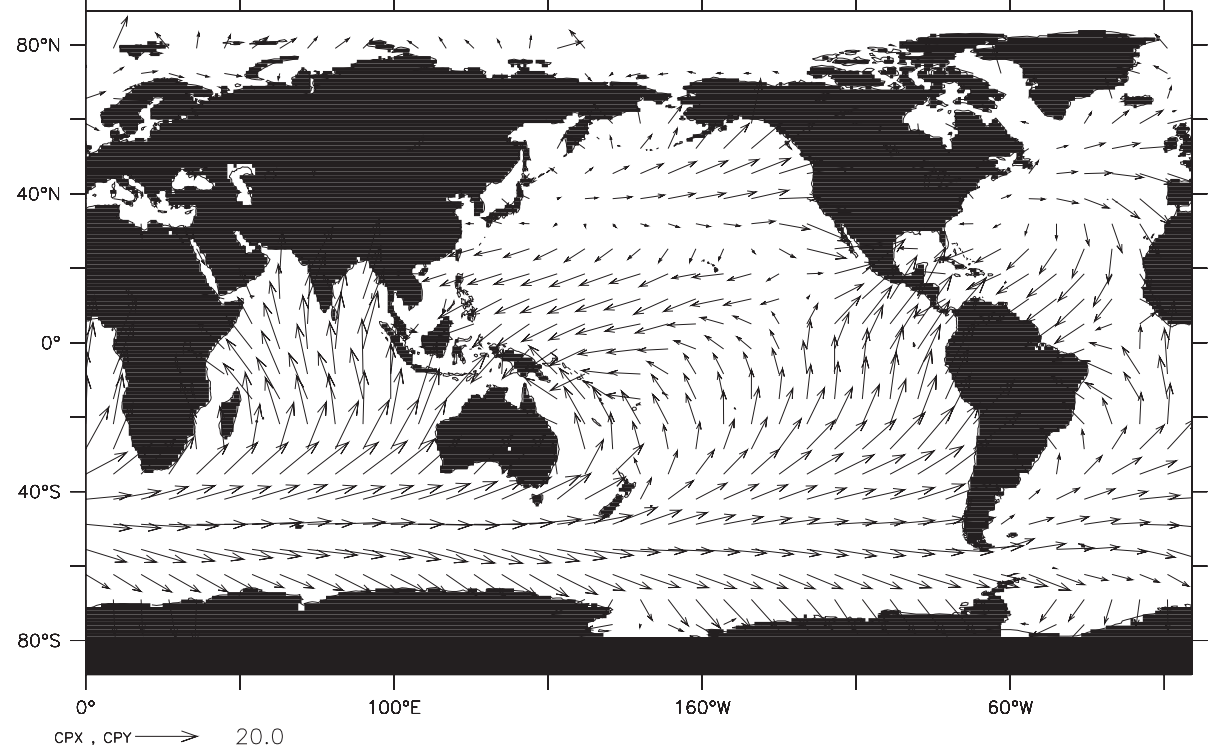

FIG. 3. (a) The 10-m wind vectors $\left(\mathrm{m} \mathrm{s}^{-1}\right)$, (b) significant wave height (m), and (c) peak phase vectors $\left(\mathrm{m} \mathrm{s}^{-1}\right)$. All quantities are calculated using the ERA-40 data averaged over 1958-2001. 
(a)

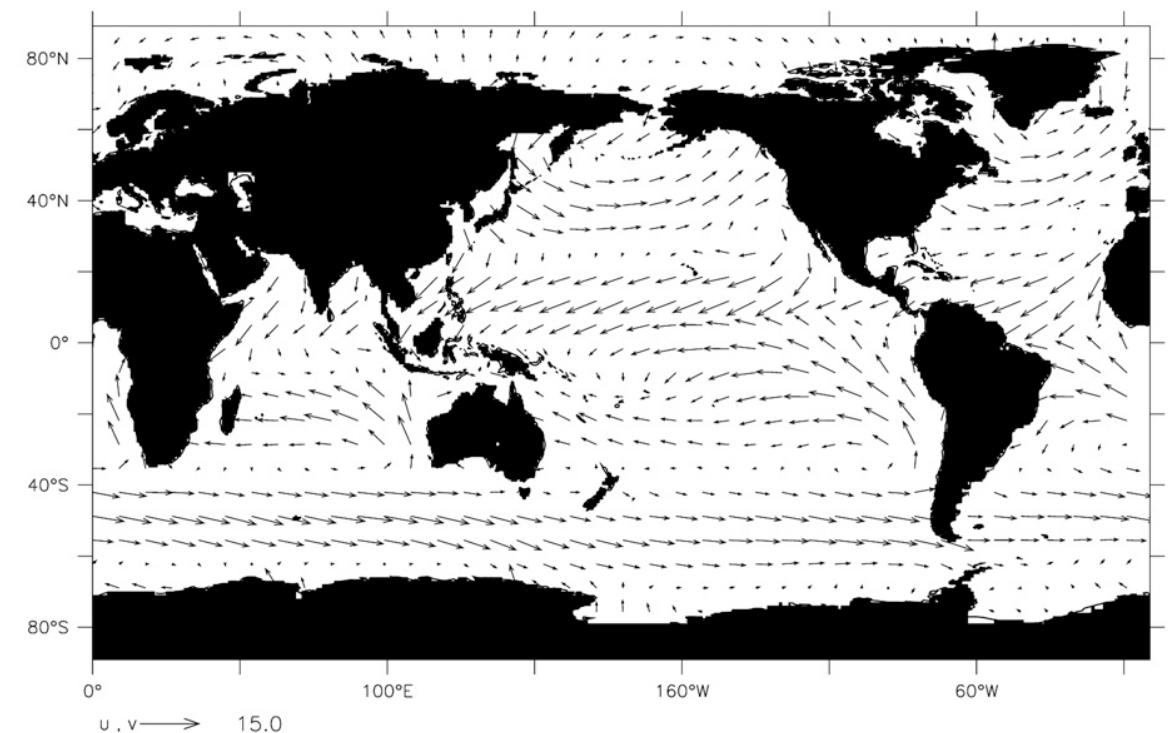

(b)

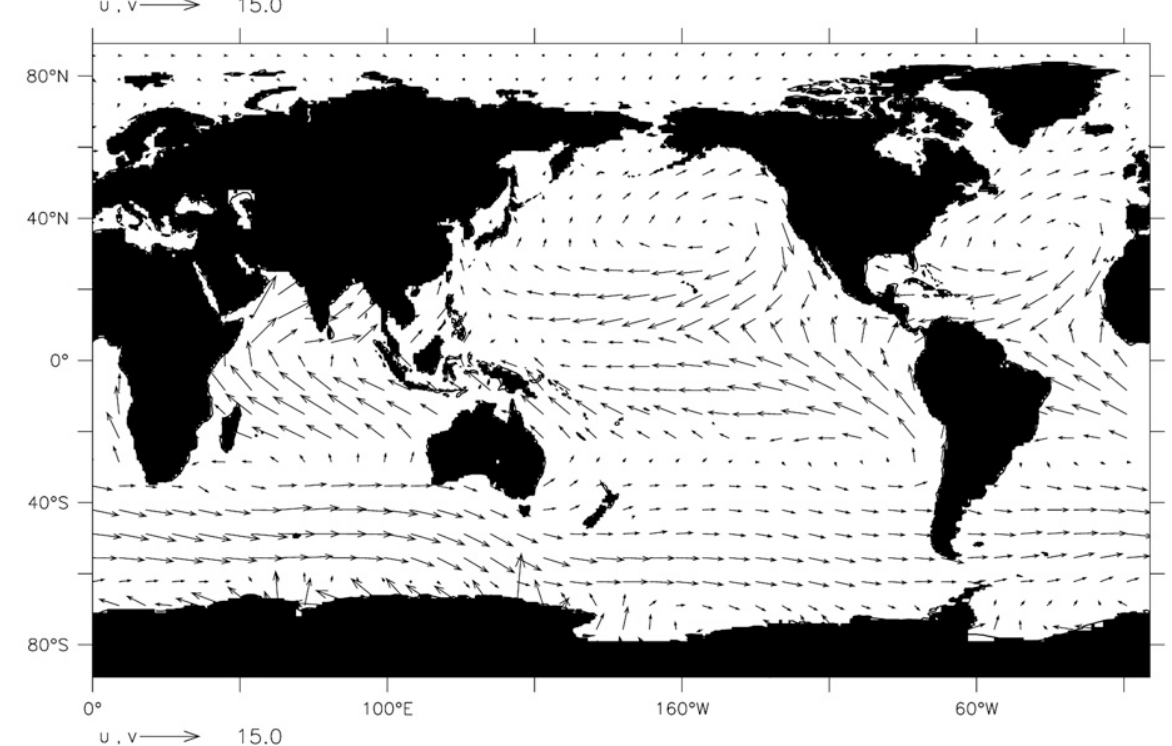

FIG. 4. The 10-m wind vectors $\left(\mathrm{m} \mathrm{s}^{-1}\right)$ from the ERA-40 data averaged over 1958-2001 for the seasons (a) DJF and (b) JJA.

does. In the North Atlantic, $U_{10}$ varies from $12 \mathrm{~m} \mathrm{~s}^{-1}$ in DJF to $7 \mathrm{~m} \mathrm{~s}^{-1}$ in JJA, whereas in the Southern Ocean between South Africa and Australia $U_{10}$ ranges from $12 \mathrm{~m} \mathrm{~s}^{-1}$ in JJA to $11 \mathrm{~m} \mathrm{~s}^{-1}$ in DJF. In the tropical Pacific and tropical Atlantic regions, the seasonal variation in $U_{10}$ is small. Typically, $U_{10}$ varies by about $1 \mathrm{~m} \mathrm{~s}^{-1}$ in most places. The greatest seasonal change in $U_{10}$ occurs in the Indian Ocean in the region of the Eurasian landmass as a result of the monsoon. In DJF, winds of $6 \mathrm{~m} \mathrm{~s}^{-1}$ are directed outward from the Eurasian landmass; by JJA, the direction has reversed and winds of $12 \mathrm{~m} \mathrm{~s}^{-1}$ are flowing toward the landmass.

Young (1999) uses a composite of radar altimeter data from the Geosat, TOPEX, and ERS-1 satellites to construct a global climatology of mean monthly values of $U_{10}$ for November 1986 to October 1995. The spatial distribution of seasonally averaged $U_{10}$ shown in Fig. 4 compares favorably with the values of mean monthly $U_{10}$ computed by Young (1999). As in Fig. 4, the mean monthly $U_{10}$ obtained from the altimeter data peak in the winter hemisphere storm track. Because Young (1999) computes monthly averages, the magnitudes of the peaks are slightly higher than those in Fig. 4. The increased values of $U_{10}$ observed in Fig. 4 in the Indian Ocean during JJA are also observed in the July averages of $U_{10}$ obtained from the altimeter data. Overall, the seasonal climatologies of $U_{10}$ computed here using the ERA-40 data are consistent with the monthly-mean 

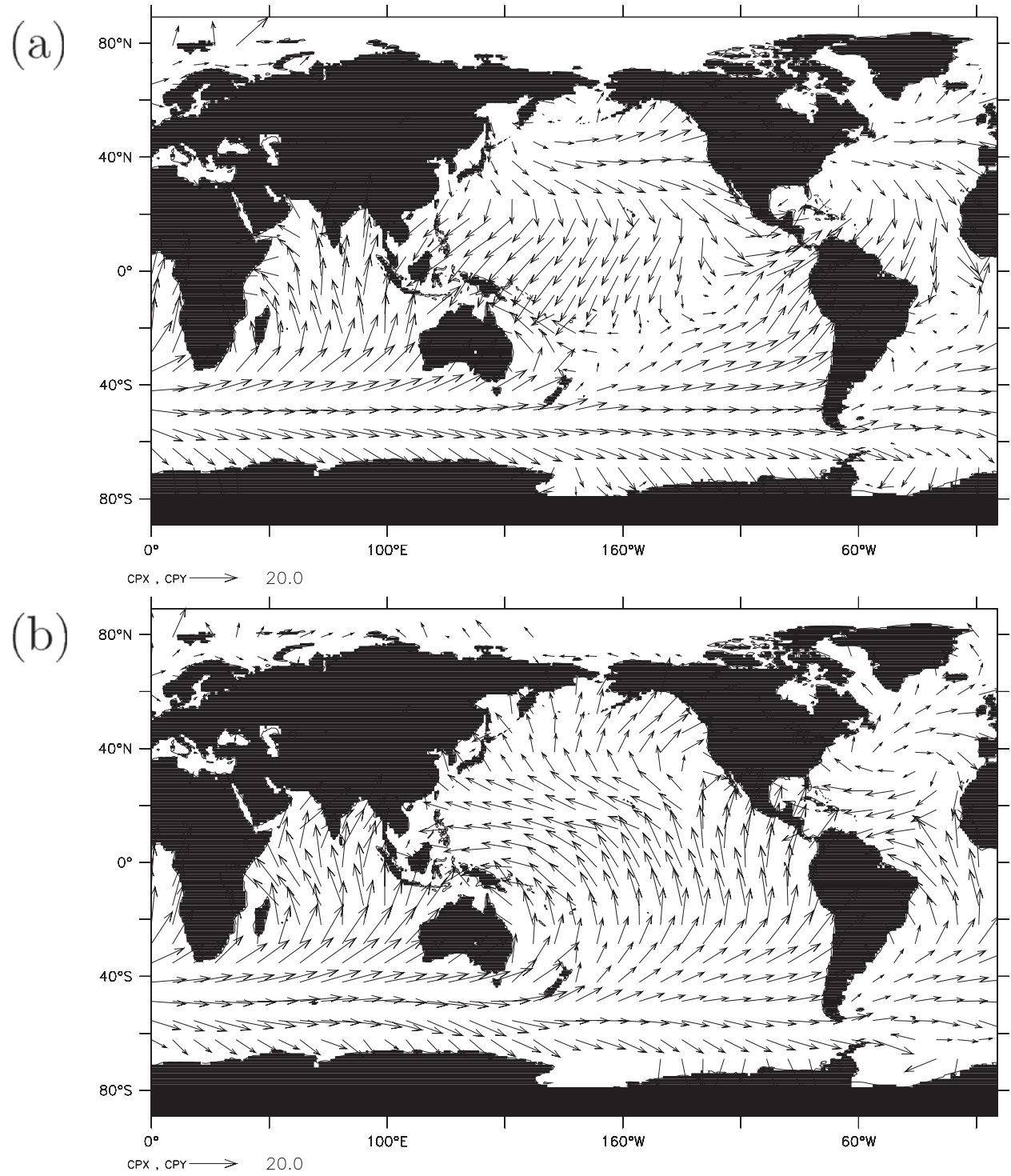

FIG. 5. As in Fig. 4, but for peak phase vectors.

climatologies computed by Young (1999). It is noted that ERS data are assimilated into ERA-40; therefore, the climatologies are not completely independent.

Figure 5 shows $c_{p}$ averaged over 1958-2001 for the seasons DJF and JJA. High winds throughout the year in the Southern Ocean mean that swell propagates out of the Southern Ocean all year. In the Northern Hemisphere storm tracks, winds are much higher in DJF than JJA; therefore, swell only originates from these regions during DJF. As a result, during DJF when the Northern Hemisphere storm tracks are most active, the front that separates swell propagating northward out of the Southern Ocean from swell propagating southward out of the Northern Hemisphere storm tracks is shifted farther south than in the annual mean. By JJA, the front has disappeared because of the weakening of the Northern Hemisphere storm tracks, and swell propagation is predominantly northward. In DJF, the peak values of $c_{p}=20 \mathrm{~m} \mathrm{~s}^{-1}$ occur in the east equatorial Pacific when swell is generated in both hemispheres. In JJA, the peak values of $c_{p}=22 \mathrm{~m} \mathrm{~s}^{-1}$ occur in the east Indian Ocean corresponding to when $U_{10}$ in the adjacent part of the Southern Ocean peaks. In the Southern Ocean, where the seasonal variation in $U_{10}$ is less than $2 \mathrm{~m} \mathrm{~s}^{-1}, c_{p}$ varies by only $3 \mathrm{~m} \mathrm{~s}^{-1}$; in the North Atlantic, where there is a larger seasonal variation in $U_{10}, c_{p}$ varies by $5 \mathrm{~m} \mathrm{~s}^{-1}$. This section has shown that the ERA-40 climatology is qualitatively consistent with previous wave climatologies. The climatologies presented in this section demonstrate that the local wave conditions are not necessarily tied to 


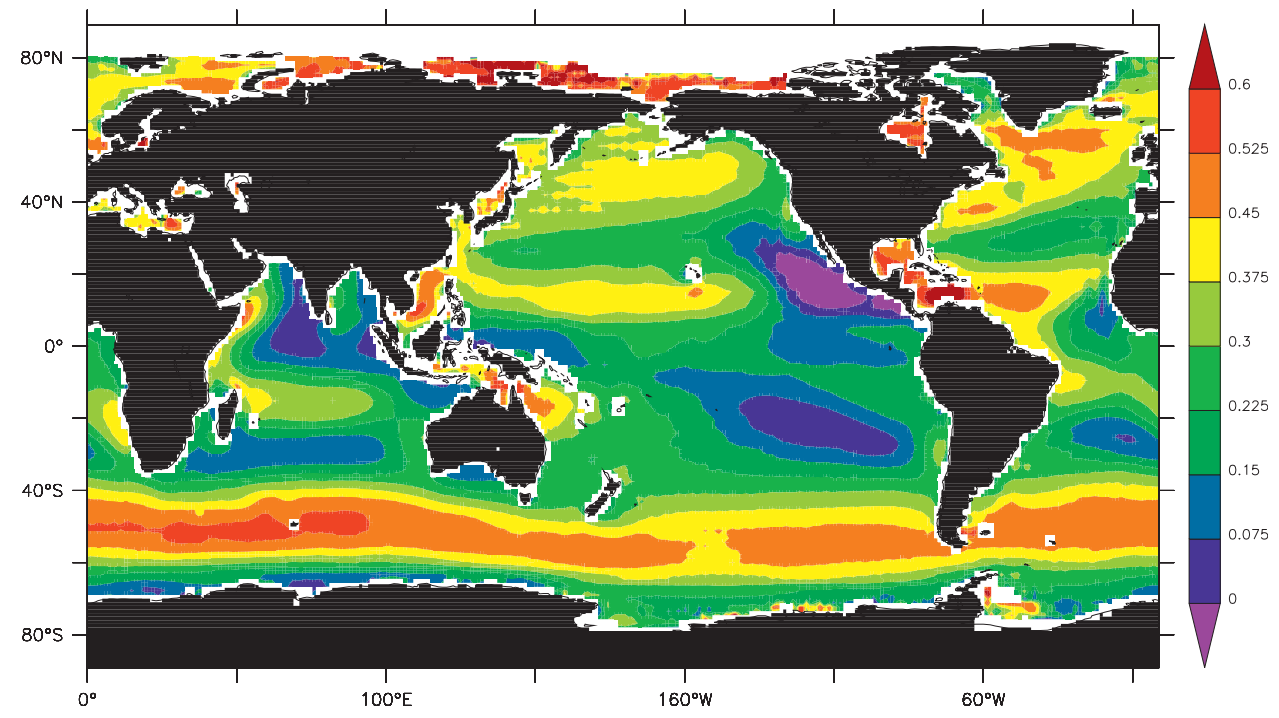

FIG. 6. Inverse wave age calculated using the ERA-40 wind and wave data averaged over 1958-2001.

the local wind conditions. High winds associated with the low pressure systems that pass through the midlatitude storm tracks generate large wind waves with high peak phase speeds. These propagate meridionally out of the storm tracks as swell. As a result, the ocean can be broadly categorized into two regimes: wind waves, which dominate in the midlatitude storm tracks and are strongly coupled to the local wind, and swell, which dominates elsewhere and is not strongly coupled to the local wind. Therefore, as noted by Edson et al. (2007), we conclude that the wind and waves are rarely in equilibrium. This is especially clear in the seasonal plots. The results of this section highlight the importance of using wave data for global wave studies, because the waves cannot be assumed to be fully developed and in equilibrium with the local surface wind.

\section{Characterizing the wind-wave regimes}

Now that the relationship between the global wave field and the global wind field has been established, the next step is to develop a climatology of $\left(U_{10} \cos \theta\right) / c_{p}$ that will quantify the degree of coupling between wind and waves. The aim of this section is to identify whether there are some regions of the ocean that are primarily in the wind-driven wave regime and others that are predominantly in the wave-driven wind regime.

\section{a. A global climatology of inverse wave age}

To determine the spatial distribution of the two windwave regimes, the ERA-40 data are used to produce a global climatology of the inverse wave age. Figure 6 shows the quantity $\left(U_{10} \cos \theta\right) / c_{p}$ averaged over 1958-2001.
The pattern in the global climatology of $\left(U_{10} \cos \theta\right) / c_{p}$ that emerges is a composite of the zonal variation of $c_{p}$ and the meridional variation of $U_{10}$.

As well as being a useful indicator of the wind-wave regime, the inverse wage age is also a good indicator of the degree of coupling between the wind and the waves: the higher the inverse wave age, the more strongly the waves are coupled to the wind (i.e., the waves require more momentum from the wind to grow). Figure 6 shows that the waves are most strongly coupled to the wind in the midlatitude storm tracks where wind speeds are highest, meaning there is more momentum available to the waves than in regions of lower wind.

In the storm tracks where wind speeds are highest and the difference between $c_{p}$ and $U_{10}$ is only a few meters per second, the inverse wave age is high. The maximum values of $\left(U_{10} \cos \theta\right) / c_{p}$ in the Southern Ocean are greater than 0.5 and coincide with the peak values of $U_{10}$ found between South Africa and Australia. High values of $\left(U_{10} \cos \theta\right) / c_{p}$ are also found in the Arctic Ocean and in enclosed and semienclosed seas where $c_{p}$ is limited by the available fetch. Outside of the storm tracks where $U_{10}$ is reduced, $\left(U_{10} \cos \theta\right) / c_{p}$ is generally lower. The exception to this is the trade wind regions in the North Pacific and North Atlantic where the values of $\left(U_{10} \cos \theta\right) / c_{p}$ are the same as in the Northern Hemisphere storm tracks. As with $c_{p}$, there is a meridional variation in $\left(U_{10} \cos \theta\right) / c_{p}$ in the tropics and subtropics, with the lowest values of $\left(U_{10} \cos \theta\right) / c_{p}$ occurring on the east side of the ocean basins, where $c_{p}$ is highest.

Although the results from Fig. 6 imply that no oceanic region has an inverse wave age greater than 0.75 in the mean, there is significant variability about this mean. 
For example, the inverse wave age in a characteristic location of the Southern Ocean has a mean and standard deviation of $0.546 \pm 0.320$ and therefore experiences significant periods of growing seas. This topic is covered further in section $4 \mathrm{c}$.

A striking feature of Fig. 6 is the existence of large regions of the oceans where $\left(U_{10} \cos \theta\right) / c_{p}<0.15$ so that upward momentum transfer might be prevalent or at least the downward momentum flux will be reduced because of an upward momentum flux from swell. Such behavior is found in the Indian Ocean, the east Pacific, and east Atlantic between $40^{\circ} \mathrm{N}$ and $40^{\circ} \mathrm{S}$. These regions coincide with the minimum values of $U_{10}$ and the peak values of $c_{p}$, and they also correspond to the three swell pools identified by Chen et al. (2002). The inverse wave age is also less than 0.15 in the western equatorial Pacific, where $U_{10}$ is particularly low, generally less than $5 \mathrm{~m} \mathrm{~s}^{-1}$.

Negative values of $\left(U_{10} \cos \theta\right) / c_{p}$ occur when $\theta$ is greater than $90^{\circ}$ (i.e., in regions of counterswell). These regions are of interest because previous studies (e.g., Donelan et al. 1997) have observed an enhanced air-sea momentum flux during counterswell conditions. The only region where the annual average of $\left(U_{10} \cos \theta\right) / c_{p}$ is less than zero is in the east Pacific, off the coast of Mexico. Here, the winds are moving west away from the land, but swell originating from the Southern Ocean is traveling toward the northeast.

In most of the open ocean, the waves are on average neither in the wind-driven wave regime [i.e., $\left(U_{10} \cos \theta\right) /$ $c_{p}>0.83$ ] nor the wave-driven wind regime [i.e., $0<$ $\left.\left(U_{10} \cos \theta\right) / c_{p}<0.15\right]$. This implies that the sea state is mixed, composed of both wind sea and swell. This conclusion ties in well with the findings of Drennan et al. (2003) and the results of section 3, which showed that in most of the global ocean $c_{p}$ is not aligned with $U_{10}$ and has a magnitude that exceeds the fully developed value of $1.2 U_{10}$, suggesting that nonlocal wave components (i.e., swell) are generally present.

Figure 7 shows $\left(U_{10} \cos \theta\right) / c_{p}$ averaged over 1958-2001 for the seasons DJF and JJA. As with the annual mean, $U_{10}$ appears to have the largest effect on the spatial distribution of $\left(U_{10} \cos \theta\right) / c_{p}$ in the midlatitude storm tracks and $c_{p}$ appears to have the larger influence in the tropics and subtropics.

In the east Atlantic and east Pacific regions, $c_{p}$ peaks in DJF when swell is originating from both hemispheres. As a result, the spatial extent of the regions where $0<$ $\left(U_{10} \cos \theta\right) / c_{p}<0.15$ is greater in DJF than in JJA. There are also more regions where $\left(U_{10} \cos \theta\right) / c_{p}<0$ in DJF than in JJA. This is because the waves have a stronger eastward component in DJF than in JJA, whereas the winds are consistently easterly. In DJF, winds exceeding $8 \mathrm{~m} \mathrm{~s}^{-1}$ in the west Pacific Ocean result in $\left(U_{10} \cos \theta\right) / c_{p}$ being greater than 0.45 . In JJA, when $U_{10}$ is usually less than $5 \mathrm{~m} \mathrm{~s}^{-1}$ and $c_{p}$ is greater than $14 \mathrm{~m} \mathrm{~s}^{-1}$, the inverse wave age in the equatorial west Pacific is in the range $0<$ $\left(U_{10} \cos \theta\right) / c_{p}<0.15$.

In the Indian Ocean in DJF, there is a large region to the north where $\left(U_{10} \cos \theta\right) / c_{p}<0$. This is because the waves are propagating northward out of the Southern Ocean, but the winds are moving from the land toward the ocean. In JJA, when strong southwesterly monsoon winds in excess of $12 \mathrm{~m} \mathrm{~s}^{-1}$ are blowing toward the land, the inverse wave age in the northeast Indian Ocean is greater than 0.6. This indicates that the waves are strongly forced by the wind. Fast waves originating from the Southern Ocean are present throughout the year in the Indian Ocean. Therefore, in the vicinity of the subtropical high and off the coast of Indonesia, where wind speeds are consistently low, the inverse wave age is less than 0.15 . During JJA, the region off the west coast of Australia is in the wave-driven wind regime. This is because more extreme storms pass through the adjacent part of the Southern Ocean than in DJF; as demonstrated in section 3a, these intense storms generate fast-traveling swell that propagates northeast across the Indian Ocean.

This section has shown that the intense storms in the midlatitude storm tracks result in wind-forced waves with high values of $\left(U_{10} \cos \theta\right) / c_{p}$. The swell generated by these storms propagates into the tropics, where wind speeds are much lighter, leading to lower values of $\left(U_{10} \cos \theta\right) / c_{p}$. In the south and east Indian Ocean, the equatorial western Pacific, the east Pacific, and the east Atlantic where $c_{p}$ peaks and $U_{10}$ is low, the climatology of inverse wave age predicts that the wave-driven wind regime will occur.

\section{b. Frequency of occurrence}

The climatology of inverse wave age has identified the regions where the mean wind-wave regime is the winddriven wave regime or the wave-driven wind regime, but it does not identify how frequently these regimes occur. Averaging will tend to smooth the peaks in the inverse wave age. Because we are interested in distinguishing which areas of the ocean are dominated by either high or low values of $\left(U_{10} \cos \theta\right) / c_{p}$, a different technique is now applied. A variable is defined that is 1 if the inverse wave age is in the range $0-0.15$ (i.e., the wave-driven wind regime) and 0 otherwise. Taking an average of this variable provides the fraction of time that the ocean is in the wave-driven wind regime (i.e., the frequency of occurrence of the wave-driven wind regime).

Figure 8 shows the frequency of occurrence of the wavedriven wind regime, averaged over 1958-2001. This regime occurs most frequently, more than $40 \%$ of the time in some places, on the eastern side of the Indian, Pacific, 


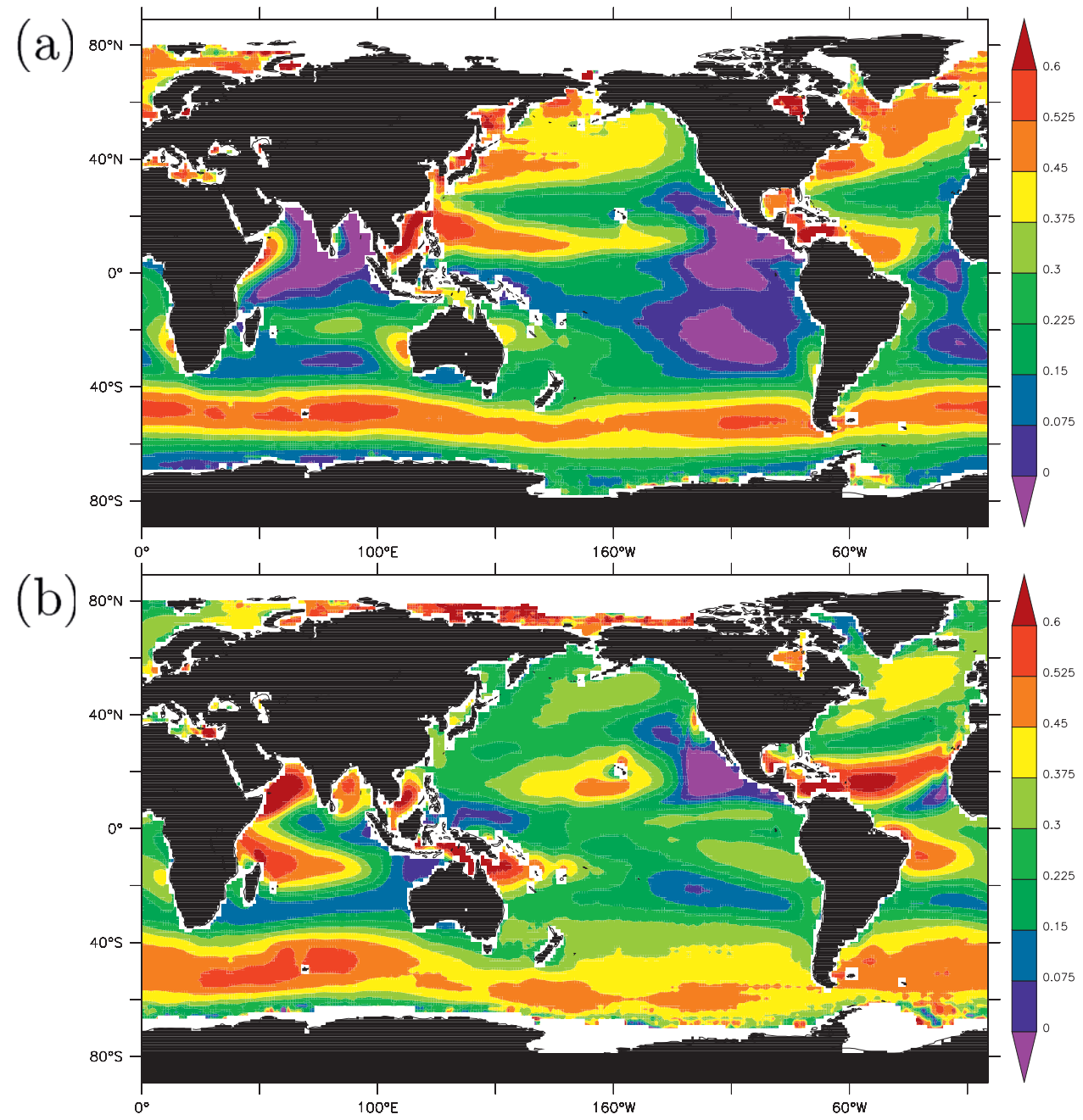

FIG. 7. As in Fig. 6, but for (a) DJF and (b) JJA.

and Atlantic Oceans, corresponding to the three swell pools identified by Chen et al. (2002). It was shown in Fig. 3 that, in these regions, $U_{10}$ is consistently low and $c_{p}$ is consistently high. In the Indian Ocean, just off the Indonesian coast, the wave-driven wind regime occurs more than $40 \%$ of the time. In the Pacific Ocean, the wave-driven wind regime occurs most frequently off the Southern California coast and off the west coast of South America, where $c_{p}$ peaks. The lower values of $c_{p}$ in the Atlantic Ocean means that the wave-driven wind regime is less common here than in the Pacific, although it still occurs more than $25 \%$ of the time just off the coast of West Africa.

Although the wave-driven wind regime is most common in the east Indian Ocean, east Pacific Ocean, and east Atlantic Ocean, it is not confined to these regions. In a large proportion of the South Pacific, between $5^{\circ} \mathrm{N}$ and $40^{\circ} \mathrm{S}$, where $c_{p}$ is high and $U_{10}$ low, the wave-driven wind regime occurs at least $15 \%$ of the time. In the western tropical Pacific, where wind speeds are particularly low, this regime occurs over $25 \%$ of the time. The wave-driven wind regime is less common in the Northern Hemisphere, because the Northern Hemisphere storm tracks are only active during DJF so that the annual average values of $c_{p}$ are lower than in the Southern Hemisphere. The intense storms that pass through the Southern Ocean generate large amounts of swell that propagates into the Indian Ocean so that the wind-driven wave regime occurs at least $10 \%$ of the time in most of the Indian Ocean. Unsurprisingly, in the Southern Ocean and in the Northern Hemisphere storm track, where wind speeds are highest on average, this regime occurs less than $10 \%$ of the time. In enclosed and semienclosed seas where the fetch is limited and wave speeds are low, the wave-driven wind regime occurs less than $10 \%$ of the time and in many of these areas less than $5 \%$ of the time.

The magnitude of the air-sea momentum flux is dependent on wave slope (Belcher and Hunt 1993). Waves 


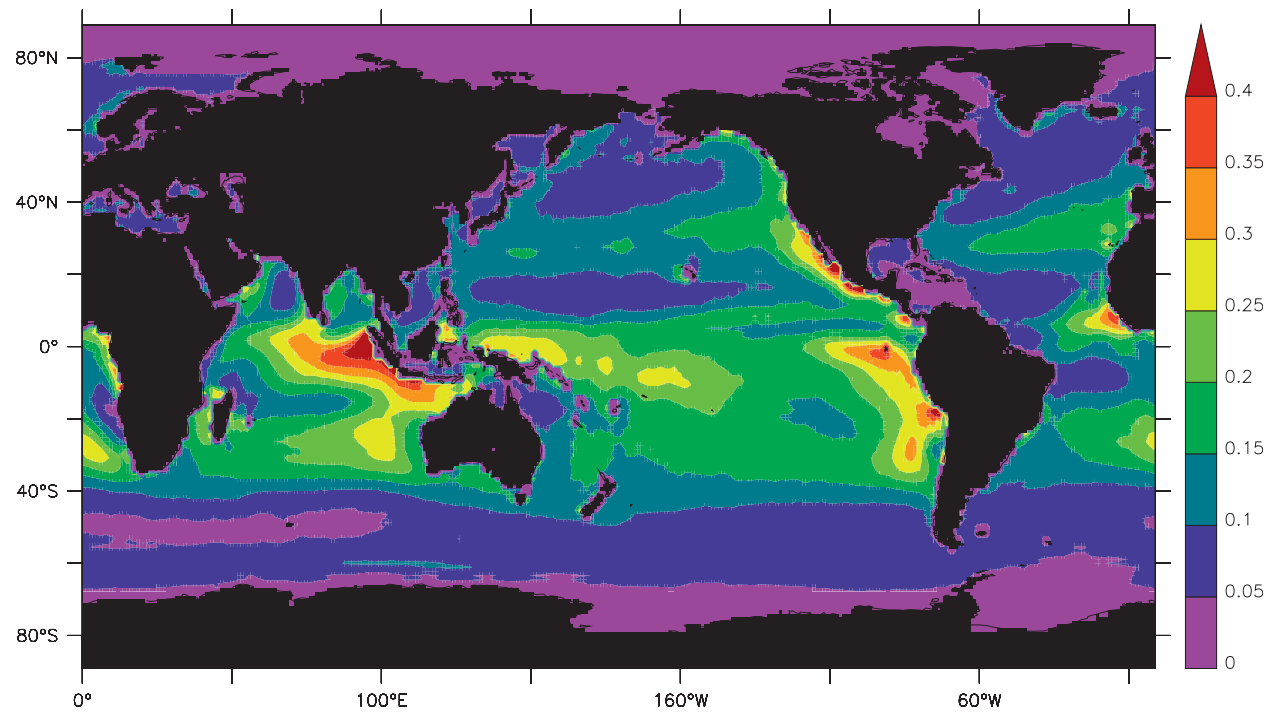

FIG. 8. The frequency of occurrence of wave-driven winds, calculated using the ERA-40 wind and wave data averaged over 1958-2001.

with steeper slopes are more strongly coupled to the wind and result in a greater magnitude air-sea momentum flux than waves of shallower slope. Figure 3 shows that, in the regions where $c_{p}$ is highest, the significant wave heights are typically less than $2 \mathrm{~m}$, which suggests that these waves have very small slopes and are therefore only weakly coupled to the wind. As such, the regions where we expect the strongest wave-driven winds are the regions where $\left(U_{10} \cos \theta\right) / c_{p}<0.15$ closest to the generation region (i.e., the southern Indian Ocean, the South Pacific, and the South Atlantic).

The frequency of occurrence of the wind-driven wave regime has been determined in a similar manner: a variable is defined that is 1 if $\left(U_{10} \cos \theta\right) / c_{p}>0.83$ (i.e., the winddriven wave regime) and zero otherwise. Averaging this variable provides the fraction of time that the ocean is in the wind-driven wave regime. Figure 9 shows the frequency of occurrence of the wind-driven wave regime in the period 1958-2001. Wind-driven waves occur most often in the regions where wave-driven winds occur least often. However, the presence of swell in most of the global ocean means that pure wind-driven seas are less common than wave-driven winds. The wind-driven wave regime occurs most frequently in the Southern Ocean, the Northern Hemisphere storm tracks, and in enclosed seas. This is in agreement with Chen et al. (2002), who

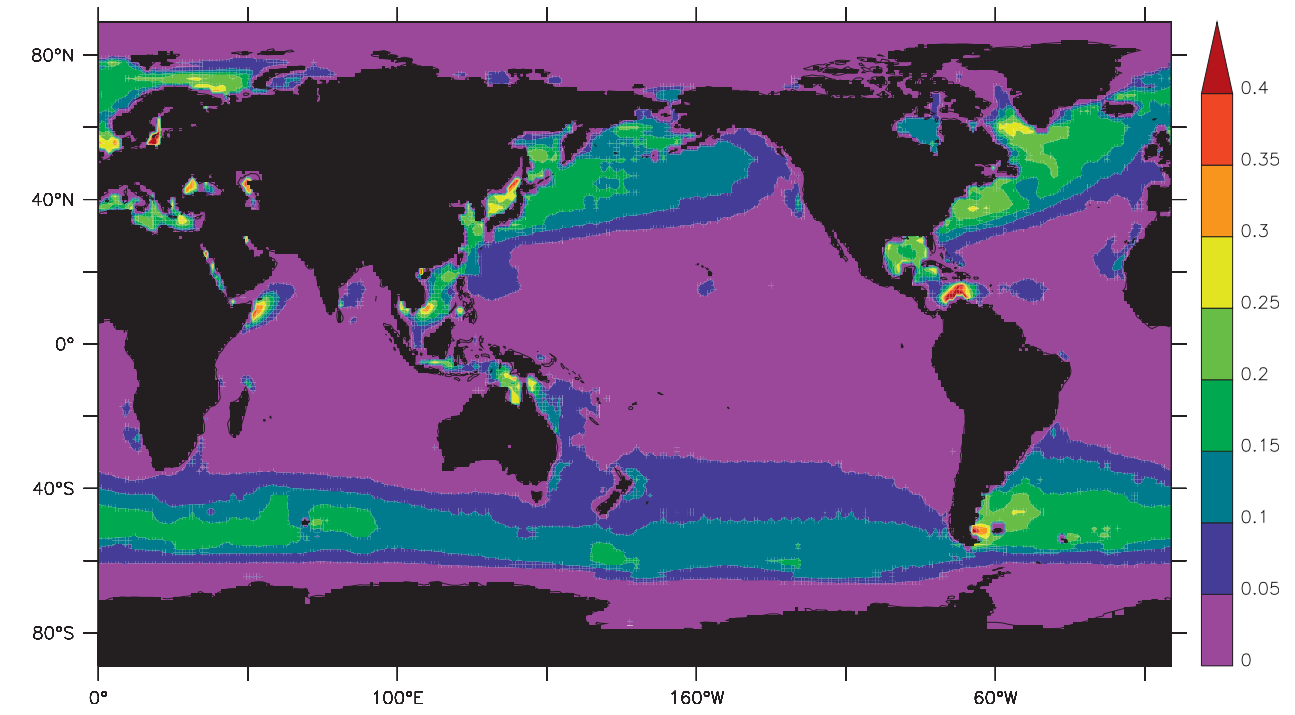

FIG. 9. As in Fig. 8, but for wind-driven waves. 


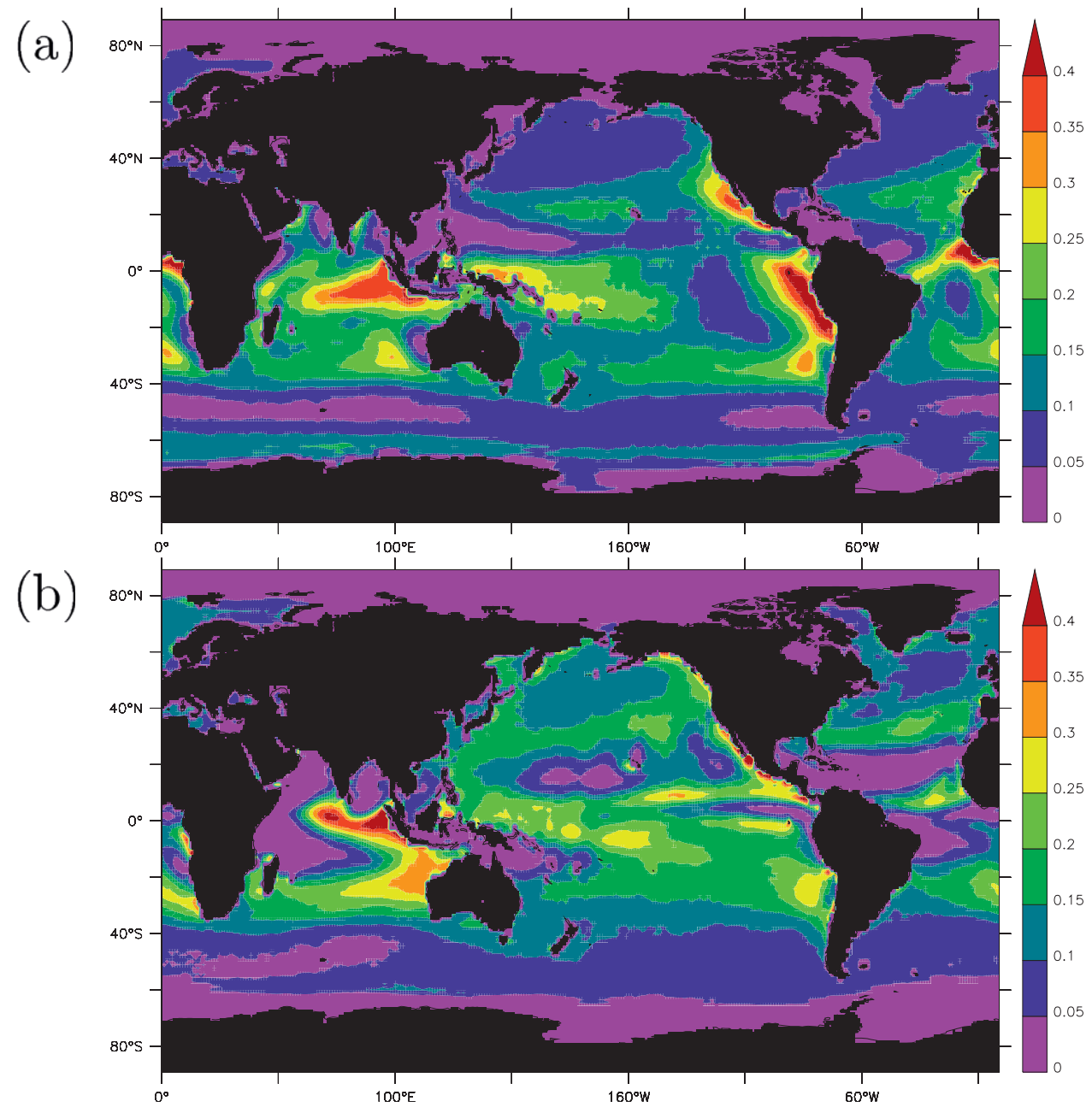

FIG. 10. As in Fig. 8, but for (a) DJF and (b) JJA.

find that wind seas are most common in the midlatitude storm tracks. In agreement with Drennan et al. (2003), the wind-driven wave regime is most common in enclosed seas where $c_{p}$ is limited by the available fetch. In these regions, this regime occurs more than $30 \%$ of the time. In the Southern Ocean and Northern Hemisphere storm tracks, where wind speeds are high, the wind-driven wave regime occurs more than $10 \%$ of the time. To the east of the Drake Passage (south of South America) and in the Northern Hemisphere storm tracks in the west Atlantic and west Pacific, the regime occurs more than $15 \%$ of the time. This is because the wave spectrum develops with fetch, so the peak wave speeds are reduced toward the western boundaries.

The presence of fast-traveling swell combined with low wind speeds in the tropics and subtropics, between $40^{\circ} \mathrm{N}$ and $40^{\circ} \mathrm{S}$, results in the wind-driven wave regime occurring less than $5 \%$ of the time. The exception is the northeast Indian Ocean, where the wind-driven wave regime occurs more than $20 \%$ of the time. As seen in Fig. 3, the annual average wind speeds are higher in this region than in the rest of the Indian Ocean.

Figure 10 shows the frequency of occurrence of wavedriven winds averaged over 1958-2001 for the seasons DJF and JJA. In DJF, when $U_{10}$ is higher in the Northern Hemisphere than in the Southern Hemisphere, the wavedriven wind regime is more prevalent in the Southern Hemisphere. Because both the Northern Hemisphere and Southern Hemisphere storm tracks are active in DJF, $c_{p}$ is higher in the Atlantic and Pacific Oceans during DJF than in JJA. As a result, the wave-driven wind regime occurs more than $20 \%$ of the time in the western tropical Pacific and more than $40 \%$ of the time in the eastern tropical Pacific and eastern tropical Atlantic regions.

In JJA, the wave-driven wind regime is less prevalent in the Atlantic, because $c_{p}$ is lower than in DJF. In both the Pacific and Atlantic Oceans, the peaks in the frequency of occurrence of the wave-driven wind regime are 


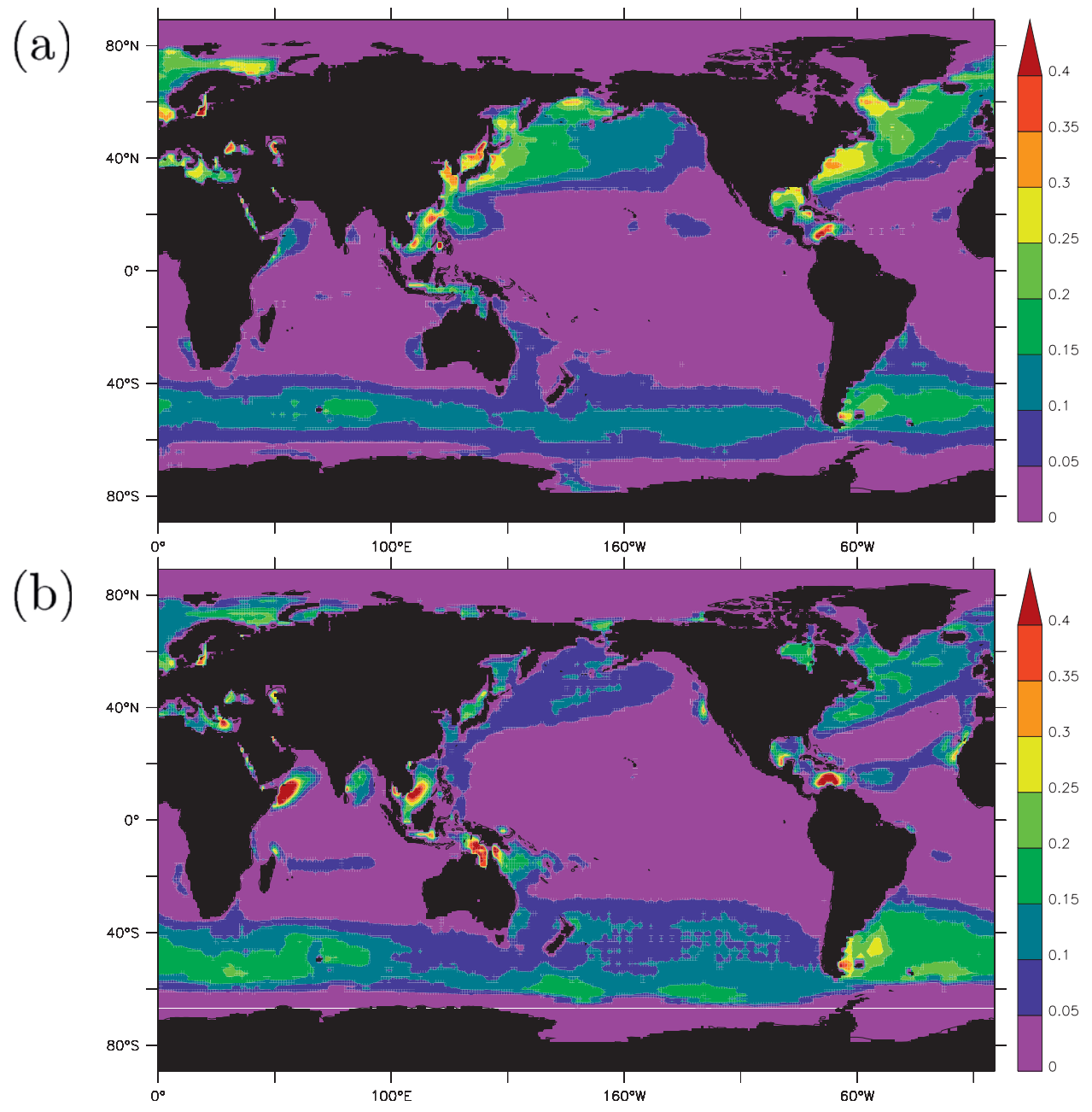

FIG. 11. As in Fig. 9, but for (a) DJF and (b) JJA.

less than in DJF: there are only a few small regions where the regime occurs more than $30 \%$ of the time, and in most of the basins the wave-driven wind regime occurs less than $25 \%$ of the time. The reduced wind speeds in the Northern Hemisphere storm tracks in JJA mean that the wave-driven wind regime is more prevalent here than in DJF. The regime is also more prevalent here than in the Southern Ocean during summer (i.e., DJF).

In DJF, the wave-driven wind regime is more prevalent in the Indian Ocean than in JJA, but the peaks occur in JJA when the regime occurs more than $40 \%$ of the time off the Indonesian coast and more than $30 \%$ of the time off the coast of Australia. This is because in most of the Indian Ocean $U_{10}$ is lower in DJF than in JJA, except close to Australia and Indonesia, where $U_{10}$ is lower in JJA. Wave speeds are higher in the Indian Ocean in JJA, especially toward the east of the basin. As a result, wavedriven winds occur less in general in the Indian Ocean during JJA but are more frequent toward the east than in DJF.

Figure 11 shows the frequency of occurrence of winddriven waves averaged over 1958-2001 for the seasons DJF and JJA. The wind-driven wave regime is most prevalent in the winter hemisphere storm tracks, where wind speeds are at their peak. In DJF, the wind-driven wave regime occurs as much as $30 \%$ of the time in the North Atlantic where $U_{10}$ peaks and as much as $25 \%$ of the time in the North Pacific. In the Southern Ocean during this season, the wind-driven wave regime occurs around $15 \%$ of the time. In JJA, when the most intense storms pass through the Southern Ocean, the wind-driven wave regime occurs more than $20 \%$ of the time in some places. During JJA, this regime occurs less than $20 \%$ of the time in the North Atlantic storm track and less than $15 \%$ of the time in the North Pacific storm track. The seasonal variation in the occurrence of wind-driven waves is greater in the Northern Hemisphere storm tracks than 
in the Southern Ocean, because the seasonal variation in the wind and therefore peak wave speeds is greater in the Northern Hemisphere storm tracks.

The presence of fast-traveling swell in the tropics means that the wind-driven wave regime is uncommon throughout the year. The exception to this is the northeast Indian Ocean in JJA when southwesterly monsoon winds are prevalent, meaning that the waves are strongly forced by the winds. During this season the wind-driven wave regime occurs more than $40 \%$ of the time in this region.

\section{c. Variability in inverse wave age}

To investigate the variability in the inverse wave age and to study what happens when $\left(U_{10} \cos \theta\right) / c_{p}$ is in neither of the two extremes, histograms of inverse wave age have been plotted at various locations. Four locations have been chosen: the tropical eastern Indian Ocean $\left(5^{\circ} \mathrm{S}, 90^{\circ} \mathrm{E}\right)$, where the mean inverse wave age is $0.123 \pm$ 0.188 ; the subtropical eastern Pacific $\left(30^{\circ} \mathrm{N}, 125^{\circ} \mathrm{W}\right)$, where the mean inverse wave age is $0.144 \pm 0.245$; the Northern Hemisphere trade wind region $\left(10^{\circ} \mathrm{N}, 170^{\circ} \mathrm{W}\right)$, where the mean inverse wave age is $0.384 \pm 0.239$; and the Southern Ocean $\left(50^{\circ} \mathrm{S}, 80^{\circ} \mathrm{E}\right)$, where the mean inverse wave age is $0.546 \pm 0.320$.

Figure 12 shows the distribution of inverse wave age at each of these locations. In the Indian Ocean (Fig. 12a) and the east Pacific (Fig. 12b), where the wave-driven wind regime is prevalent, the histograms are strongly biased toward low values of inverse wave age, both with peaks in the range of 0.05-0.1. In the Northern Hemisphere trade wind region (Fig. 12c) and the Southern Ocean (Fig. 12d), where the wind-driven wave regime is prevalent, the histograms are biased toward higher values of inverse wave age: in the Northern Hemisphere trade wind region the peak lies in the range 0.4-0.45, and in the Southern Ocean the histogram peaks in the range $0.6-0.65$. Figure $12 \mathrm{~d}$ shows a larger spread in the values of inverse wave age, with values ranging from -1 to 1.5 , compared to Figs. $12 \mathrm{a}-\mathrm{c}$, where values range from -0.5 to 1 . The large variability in $\left(U_{10} \cos \theta\right) / c_{p}$ in the Southern Ocean is caused by the large range in wind speeds and directions, as observed in Fig. 1. In the tropics and subtropics, Fig. 2 shows that wind speeds are much less variable. Therefore, the variability in $\left(U_{10} \cos \theta\right) / c_{p}$ in these regions must come from $c_{p}$.

Figure 12 also shows $U_{10} / c_{p}$ for the year 1999 from the National Data Buoy Center (NDBC) mooring 44008 in the North Atlantic (Fig. 12e) and the corresponding ERA-40 data for this location (Fig. 12f). These histograms have not been corrected for wind-wave misalignment because the mean wave direction was not available for the buoy data. As a result, there are no negative values of inverse wave age, and there is also a higher occurrence of developing seas $\left(U_{10} / c_{p}>0.83\right)$. Even so, it is clear that the data are dominated by swell in this region, with both histograms showing peaks in $U_{10} / c_{p}$ in the range 0.3-0.35. There is good agreement between the buoy data and the ERA-40 data: as well as both peaking at the same value of $U_{10} / c_{p}$, the frequency of occurrence of the peak is about $7 \%$. The main difference is that the histogram of the ERA-40 data is less smooth, which is most likely a sampling issue because the buoy data are provided hourly whereas the ERA-40 data are only every $6 \mathrm{~h}$.

The histograms of $\left(U_{10} \cos \theta\right) / c_{p}$ shown in Fig. 12 clearly demonstrate the nonequilibrium that exists between the surface wind and the waves. There are few occurrences of wind-wave equilibrium, with most values lying below 0.83 (i.e., $c_{p}$ exceeds the fully developed value). Even in the Southern Ocean and the Northern Hemisphere trade wind region, where wind speeds are high, most values of $\left(U_{10} \cos \theta\right) / c_{p}$ are less than 0.83 . This is partly due to the presence of remotely generated swell, but it is also due to the variable nature of the winds in this region.

This section has shown that the wave-driven wind regime is most prevalent in tropical regions (e.g., the Indian Ocean, the east Pacific and Atlantic Oceans, and the west Pacific) where wind speeds are consistently low and swell generated by storms in the midlatitude storm tracks is traveling at high speeds. Pure wind-driven seas are most common in the midlatitude storm tracks where wind speeds are much higher and more variable and in enclosed seas where wave speeds are limited by fetch.

\section{Discussion}

In this paper, we used the ECMWF ERA-40 data to examine the degree of local coupling between the surface wind and the waves as diagnosed by the inverse wave age. The focus has been on identifying the spatial distribution of the extremes of inverse wave age, which we interpret as diagnosing two wind-wave regimes: winddriven waves and wave-driven winds.

The waves are primarily driven by the overlying wind field, so it might be thought that the local wave conditions are strongly tied to the local wind conditions. Using the ERA-40 data to construct climatologies of the 10-m wind speed, significant wave height, and peak wave phase speed, we have shown that the wind and waves are often in a state of nonequilibrium; that is, the surface wind and waves are often misaligned, and the significant wave height and peak phase speed of the waves exceed the fully developed limit. This is an indication that nonlocal wave components (i.e., swell) generated remotely by storms are present. Using the ERA-40 data to study the passage of a storm through the Southern Ocean, we 
(a)

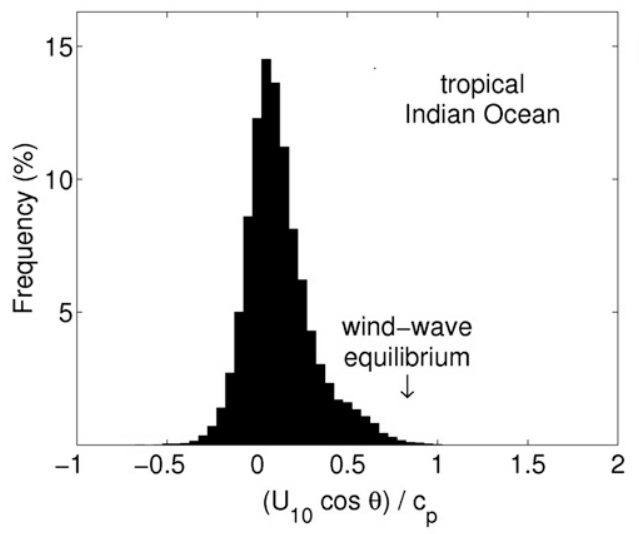

(c)

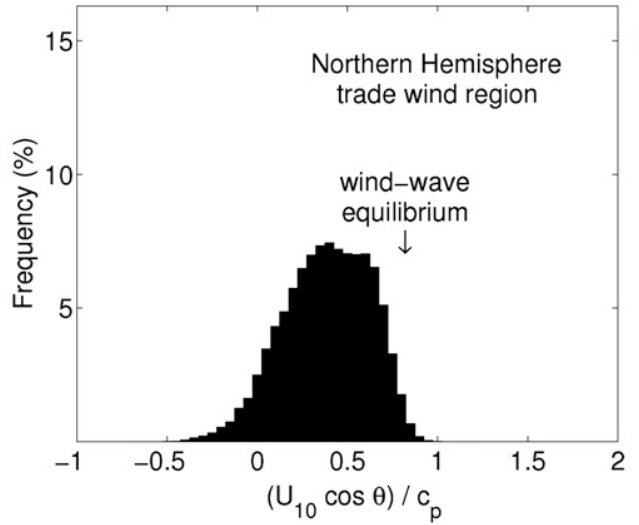

(e)

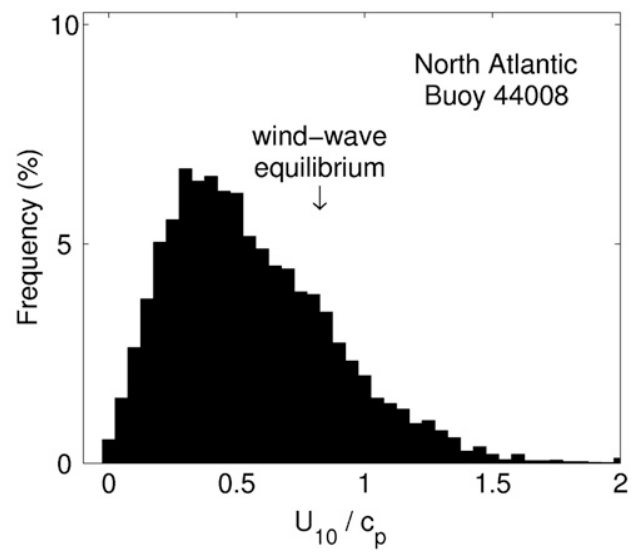

(b)

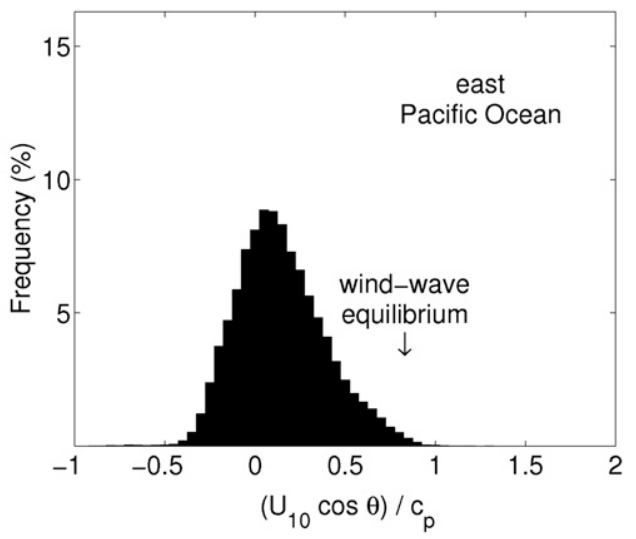

(d)

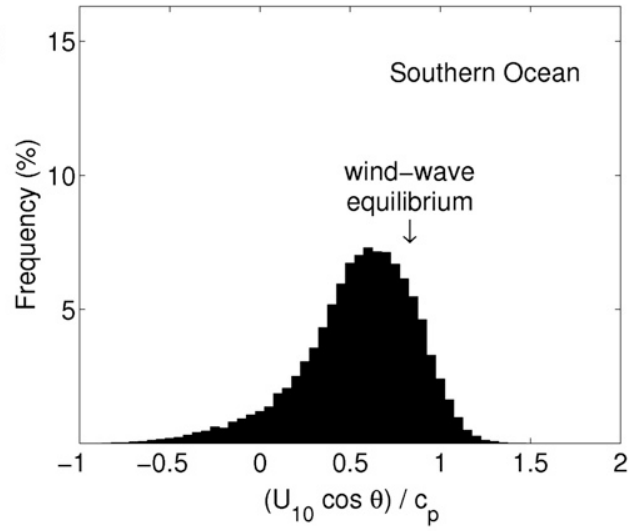

(f)

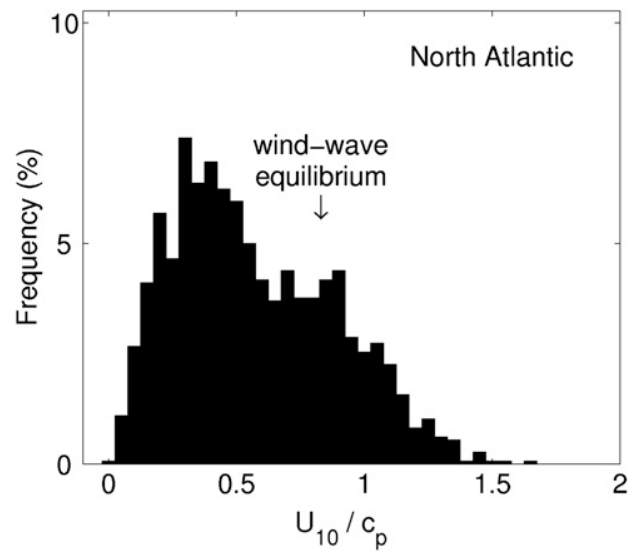

FIG. 12. Histograms of inverse wave age calculated using the ERA-40 data for $1958-2001$ at (a) $5^{\circ} \mathrm{S}, 90^{\circ} \mathrm{E}$, where the mean $\left(U_{10} \cos \theta\right) / c_{p}$ is $0.123 \pm 0.188$; (b) $30^{\circ} \mathrm{N}, 125^{\circ} \mathrm{W}$, where the mean $\left(U_{10} \cos \theta\right) / c_{p}$ is $0.144 \pm 0.245$; (c) $10^{\circ} \mathrm{N}, 170^{\circ} \mathrm{W}$, where the mean $\left(U_{10} \cos \theta\right) / c_{p}$ is $0.384 \pm 0.239$; and $(\mathrm{d}) 50^{\circ} \mathrm{S}, 80^{\circ} \mathrm{E}$, where the mean $\left(U_{10} \cos \theta\right) / c_{p}$ is $0.546 \pm 0.320$. Inverse wave age for 1999 from (e) the NDBC buoy from mooring 44008 in the North Atlantic $\left(40.5^{\circ} \mathrm{N}, 69^{\circ} \mathrm{W}\right)$ and (f) the corresponding ERA-40 data for this location.

demonstrated that strong winds associated with the intense low pressure system generate large wind waves with high peak phase speeds. These waves then propagate out of the Southern Ocean toward the tropics as swell.

Next, the ERA-40 wave data were used to diagnose the global prevalence of the two wind-wave regimes. Inverse wave age was chosen as a simple parameter to characterize wind-wave interaction, with the wind-driven wave regime occurring when $\left(U_{10} \cos \theta\right) / c_{p}>0.83$ and the wave-driven wind regime occurring when $0<\left(U_{10} \cos \theta\right) /$ $c_{p}<0.15$. The global climatology of $\left(U_{10} \cos \theta\right) / c_{p}$ shows that the wind-driven wave regime occurs most often in the Southern Ocean and the Northern Hemisphere storm tracks, where wind speeds peak. The wave-driven wind 
regime is most prevalent in the tropical eastern ocean basins, just off the coasts of Indonesia, Southern California, South America, and Africa. In these regions, wind speeds are typically low and the peak phase speeds are high.

In this paper, the inverse wave age has been used as a proxy for identifying regions where the wave-driven wind regime and upward momentum flux by swell may be important. Calculation of the air-sea momentum flux requires the entire wave spectrum to be specified. In the method used here to diagnose the global distribution of the wave-driven wind regime, the wave field has been characterized by a single parameter, $c_{p}$. Hanley and Belcher (2008) showed that, in swell-dominated conditions, the surface stress is dominated by contributions from the spectral peak. Consequently, the sign reversal of the momentum flux at the surface is determined by $\left(U_{10} \cos \theta\right) / c_{p}$, because this parameter distinguishes the part of the swell spectrum that takes momentum from the wind from the part that gives momentum to the wind. Therefore, the inverse wave age is chosen as a simple parameter that provides a first practical estimate of upward momentum flux and wave-driven winds.

Irrespective of this, the inverse wave age is a good indicator of the degree of wind-wave coupling. The climatologies show that in most regions $\left(U_{10} \cos \theta\right) / c_{p}<0.83$, indicating that swell is present, therefore resulting in a weaker coupling between the wind and waves than in pure wind sea conditions.

To identify how frequently the two wind-wave regimes occur, frequency of occurrence climatologies were produced. These showed that, in parts of the Southern Ocean and Northern Hemisphere storm tracks, the wind-driven wave regime occurs $20 \%$ of the time and that, in the eastern Indian Ocean, the equatorial west Pacific, and off the west coast of Africa, the wave-driven wind regime occurs more than $25 \%$ of the time. Histograms of $\left(U_{10} \cos \theta\right) / c_{p}$ in the Southern Ocean and the Northern Hemisphere trade wind region were shown to be biased toward high values, whereas histograms of $\left(U_{10} \cos \theta\right) / c_{p}$ in the Indian Ocean and off the Southern California coast are biased toward low values. However, all histograms demonstrate the nonequilibrium that exists between the local surface wind conditions and the local wave conditions.

In conclusion, these calculations have demonstrated that a nonequilibrium between the surface wind and waves is common. The picture that emerges is of momentum being taken up by ocean waves from the wind in the midlatitude storm tracks. A proportion of this momentum is deposited locally into the ocean driving currents. The remainder propagates away from the region of generation toward the tropics, where a proportion of the momentum flux is returned to the atmosphere through wave-driven winds.

Acknowledgments. This work was made possible by a $\mathrm{Ph} . \mathrm{D}$ studentship funded by the Natural Environmental Research Council (NERC Reference NER/S/A/2003/ 11349A). ECMWF ERA-40 data used in this study have been obtained from the British Atmospheric Data Centre.

\section{REFERENCES}

Ahrens, C. D., 2003: Meteorology Today: An Introduction to Weather, Climate, and the Environment. 7th ed. Thomson/ Brooks/Cole, 624 pp.

Alves, J. H., M. L. Banner, and I. R. Young, 2003: Revisiting the Pierson-Moskowitz asymptotic limits for fully developed wind waves. J. Phys. Oceanogr., 33, 1301-1323.

Belcher, S. E., and J. C. R. Hunt, 1993: Turbulent shear flow over slowly moving waves. J. Fluid Mech., 251, 109-148.

Caires, S., A. Sterl, J.-R. Bidlot, N. Graham, and V. Swail, 2004: Intercomparison of different wind-wave reanalyses. J. Climate, 17, 1893-1913.

Chen, G., B. Chapron, R. Ezraty, and D. Vandemark, 2002: A global view of swell and wind sea climate in the ocean by satellite altimeter and scatterometer. J. Atmos. Oceanic Technol., 19, 1849-1859.

de las Heras, M. M., G. Burgers, and P. A. E. M. Janssen, 1994: Variational wave data assimilation in a third-generation wave model. J. Atmos. Oceanic Technol., 11, 1350-1369.

Donelan, M. A., W. M. Drennan, and K. B. Katsaros, 1997: The air-sea momentum flux in conditions of wind sea and swell. J. Phys. Oceanogr., 27, 2087-2099.

Drennan, W. M., K. K. Kahma, and M. A. Donelan, 1999: On momentum flux and velocity spectra over waves. Bound.Layer Meteor., 92, 489-515.

- H. C. Graber, D. Hauser, and C. Quentin, 2003: On the wave age dependence of wind stress over pure wind seas. J. Geophys. Res., 108, 8062, doi:10.1029/2000JC000715.

Edson, J., and Coauthors, 2007: The Coupled Boundary Layers and Air-Sea Transfer experiment in low winds. Bull. Amer. Meteor. Soc., 88, 341-356.

Grachev, A. A., and C. W. Fairall, 2001: Upward momentum transfer in the marine boundary layer. J. Phys. Oceanogr., 31, 1698-1711.

Hanley, K. E., and S. E. Belcher, 2008: Wave-driven wind jets in the marine atmospheric boundary layer. J. Atmos. Sci., 65, 2646-2660.

Harris, D. L., 1966: The wave-driven wind. J. Atmos. Sci., 23, 688-693.

Hasselmann, S., and Coauthors, 1988: The WAM model-A third generation ocean wave prediction model. J. Phys. Oceanogr., 18, $1775-1810$.

Janssen, P. A. E. M., 1989: Wave-induced stress and the drag of air flow over sea waves. J. Phys. Oceanogr., 19, 745-754.

- 1991: Quasi-linear theory of wind-wave generation applied to wave forecasting. J. Phys. Oceanogr., 21, 1631-1642.

_ B. Banssen, and J.-R. Bidlot, 1997: Verification of the ECMWF wave forecasting system against buoy and altimeter data. Wea. Forecasting, 12, 763-784.

Komen, G. J., L. Cavaleri, M. Donelan, K. Hasslemann, S. Hasslemann, and P. A. E. M. Janssen, 1994: Dynamics 
and Modelling of Ocean Waves. Cambridge University Press, $520 \mathrm{pp}$.

McWilliams, J. C., and J. M. Restrepo, 1999: The wave-driven ocean circulation. J. Phys. Oceanogr., 29, 2523-2540.

Pierson, W. J., and L. Moskowitz, 1964: A proposed spectral form for fully developed wind seas based on the similarity theory of S. A. Kitaigorodskii. J. Geophys. Res., 69, 5181-5190.

Smedman, A., U. Högström, H. Bergstrom, A. Rutgersson, K. K. Kahma, and H. Pettersson, 1999: A case study of air-sea interaction during swell conditions. J. Geophys. Res., 104, $25833-25851$.
_ _ X. G. Larsen, U. Högström, K. K. Kahma, and H. Pettersson, 2003: Effect of sea state on the momentum exchange over the sea during neutral conditions. J. Geophys. Res., 108, 3367, doi:10.1029/2002JC001526.

Snodgrass, F. E., G. W. Groves, K. Hasselmann, G. R. Miller, W. H. Munk, and W. H. Powers, 1966: Propagation of ocean swell across the Pacific. Philos. Trans. Roy. Soc. London, 259A, 431-497.

Uppala, S. M., and Coauthors, 2005: The ERA-40 Re-Analysis. Quart. J. Roy. Meteor. Soc., 131, 2961-3012.

Young, I. R., 1999: Seasonal variability of the global ocean wind and wave climate. Int. J. Climatol., 19, 931-950. 